\title{
Combined vascular endothelial growth factor-A and fibroblast growth factor 4 gene transfer improves wound healing in diabetic mice
}

Agnieszka Jazwa', Paulina Kucharzewska', Justyna Leja ${ }^{1}$, Anna Zagorska', Aleksandra Sierpniowska', Jacek Stepniewski ${ }^{1}$, Magdalena Kozakowska ${ }^{1}$, Hevidar Taha' ${ }^{1}$ Takahiro Ochiya ${ }^{2}$, Rafal Derlacz ${ }^{3}$, Elisa Vahakangas ${ }^{4}$, Seppo Yla-Herttuala ${ }^{4}$, Alicja Jozkowicz ${ }^{1}$, Jozef Dulak ${ }^{1 *}$

\begin{abstract}
Background: Impaired wound healing in diabetes is related to decreased production of growth factors. Hence, gene therapy is considered as promising treatment modality. So far, efforts concentrated on single gene therapy with particular emphasis on vascular endothelial growth factor-A (VEGF-A). However, as multiple proteins are involved in this process it is rational to test new approaches. Therefore, the aim of this study was to investigate whether single AAV vector-mediated simultaneous transfer of VEGF-A and fibroblast growth factor 4 (FGF4) coding sequences will improve the wound healing over the effect of VEGF-A in diabetic (db/db) mice.
\end{abstract}

Methods: Leptin receptor-deficient $\mathrm{db} / \mathrm{db}$ mice were randomized to receive intradermal injections of PBS or AAVs carrying $\beta$-galactosidase gene (AAV-LacZ), VEGF-A (AAV-VEGF-A), FGF-4 (AAV-FGF4-IRES-GFP) or both therapeutic genes (AAV-FGF4-IRES-VEGF-A). Wound healing kinetics was analyzed until day 21 when all animals were sacrificed for biochemical and histological examination.

Results: Complete wound closure in animals treated with AAV-VEGF-A was achieved earlier (day 19) than in control mice or animals injected with AAV harboring FGF4 (both on day 21). However, the fastest healing was observed in mice injected with bicistronic AAV-FGF4-IRES-VEGF-A vector (day 17). This was paralleled by significantly increased granulation tissue formation, vascularity and dermal matrix deposition. Mechanistically, as shown in vitro, FGF4 stimulated matrix metalloproteinase-9 (MMP-9) and VEGF receptor-1 expression in mouse dermal fibroblasts and when delivered in combination with VEGF-A, enhanced their migration.

Conclusion: Combined gene transfer of VEGF-A and FGF4 can improve reparative processes in the wounded skin of diabetic mice better than single agent treatment.

\section{Introduction}

Optimum healing of a cutaneous wound requires a well orchestrated integration of the complex biological and molecular events of cell migration and proliferation, extracellular matrix (ECM) deposition, angiogenesis and remodeling $[1,2]$. One of the most common disease states associated with impaired tissue repair is diabetes mellitus [1]. Many factors contribute to chronic, nonhealing diabetic wounds, among which crucial is the

\footnotetext{
* Correspondence: jozef.dulak@uj.edu.pl

'Department of Medical Biotechnology, Faculty of Biochemistry, Biophysics

and Biotechnology, Jagiellonian University, Krakow, Poland Full list of author information is available at the end of the article
}

impairment in the production of cytokines and growth factors, such as keratinocyte growth factor (KGF), vascular endothelial growth factor-A (VEGF-A) or plateletderived growth factor (PDGF) by local inflammatory cells and fibroblasts $[1,3,4]$.

In animal models of impaired wound healing diminished neovascularization is also associated with delayed or diminished production of VEGF-A and other angiogenic growth factors [5]. VEGF-A, as the most potent angiogenic factor of the VEGF family members, exerts its mitogenic activity via its receptors VEGF-R1 (Flt-1) and VEGF-R2 (Flk-1), which are expressed mainly by endothelial cells [6]. Moreover, VEGF-A may modulate
C Biomed Central 
expression of plasminogen activator (PA) and plasminogen activator inhibitor-1 (PAI-1) in microvascular endothelial cells [7] as well as influence endothelial cellderived matrix metalloproteinases (MMPs) activity [8]. These actions contribute to the ability of VEGF-A to promote endothelial cell invasion. Accordingly, it has been shown that VEGF-A delivered either as a protein [9] or as a gene $[10,11]$ improves wound healing in diabetic mice through the stimulation of angiogenesis, re-epithelialization, synthesis and maturation of extracellular matrix.

Fibroblast growth factors (FGFs), a large family of more than 20 multifunctional proteins, stimulate proliferation in a wide range of cell types, through their binding to cell membrane tyrosine kinase receptors [12]. These FGF receptors (FGFRs) comprise 4 receptor tyrosine kinases designated FGFR-1, FGFR-2, FGFR-3, and FGFR-4 [13]. Upon receptor binding, FGFs can elicit a variety of biological responses, such as cell proliferation, differentiation and migration. These activities are critical to a wide variety of physiological as well as pathological processes including angiogenesis, vasculogenesis, wound healing, tumorigenesis, and embryonic development [14].

FGF4 is a member of FGFs family and was the first one among all FGFs to be described as an oncogene. It is expressed during early limb development and throughout embryogenesis $[15,16]$. In adults, FGF4 is found primarily in tumors, such as stomach cancer, Kaposi sarcoma, and breast cancer [17], but also to some extend in the nervous system, intestines, and testes [18]. Few years ago, also the potential therapeutic application of this growth factor has been highlighted as it has been demonstrated to play a pivotal role in the growth of newly formed capillaries and their enlargement in the process called arteriogenesis [19]. The angiogenic effects of FGF4 are related to the up-regulation of the endogenous VEGF-A expression $[19,20]$. Unlike FGF-1, -2, and -9, which lack a signal peptide (but may still be released by an alternative secretion pathway), FGF4 is efficiently secreted [21], what is rather advantageous over the other FGFs for the gene therapy. FGF4 protein is a potent mitogen for a variety of cell types of mesodermal and neuroectodermal origin, including fibroblasts and melanocytes [14]. It has also been shown to stimulate endothelial cell proliferation, migration, and protease production in vitro and neovascularization in vivo [22]. FGFR-2 is the preferred receptor for FGF4 under restricted heparan sulfate conditions [23]. Furthermore, FGF4 similarly to VEGF-A [6], binds to heparan sulfate of the extracellular matrix, what leads to its deposition near the place of synthesis [23].

So far, all efforts concentrated on single gene therapy for the treatment of impaired wound healing. However, as multiple proteins are involved in this process there might be a need to efficiently deliver more than one gene. The role of VEGF-A in the promotion of wound closure has been well documented whereas the effect of FGF4 has not been analyzed. Therefore, the aim of this study was to investigate whether FGF4 will accelerate the wound closure and whether combined AAVmediated gene therapy approach with VEGF-A and FGF4 coding sequences will improve the wound healing over the effect of VEGF-A in genetically diabetic mice.

\section{Materials and methods Reagents}

Cell culture reagents, Dulbecco's Modified Eagle's Medium (DMEM) and foetal bovine serum (FBS) were from PAA (Lodz, Poland). Recombinant human vascular endothelial growth factor (rhVEGF-A) and recombinant human fibroblast growth factor (rhFGF4) as well as hVEGF-A- and hFGF4-recognizing ELISA kits were procured from R\&D Systems Europe (Warszawa, Poland). Oligo(dT) primers, dNTPs, MMLV reverse transcriptase, $\beta$-galactosidase Enzyme Assay System and Bromodeoxyuridine (BrdU) incorporation assay were obtained from Promega (Gdansk, Poland). pAAV-MCS and pAAVLacZ plasmid vectors were obtained from Stratagene (Piaseczno, Poland). Proliferating cell nuclear antigen (PCNA) recognizing primary antibodies (clone PC10) and Animal Research Kit (ARK) Peroxidase were procured from DAKO (Gdynia, Poland). Streptavidin Alexa Fluor 546 and Alexa Fluor 488 secondary antibodies were obtained from Invitrogen (Warszawa, Poland). All other reagents and chemicals, unless otherwise stated, were purchased from Sigma (Poznan, Poland).

\section{$A A V$ vector preparation and characterization}

Four AAV serotype 2 vectors (AAV2) were used in the present study (Figure 1a). They were carrying either LacZ reporter (control) gene under the control of constitutive CMV (cytomegalovirus) immediate early promoter or human 165-isoform of VEGF-A under the control of strong CMV promoter or human FGF4 under the control of chicken $\beta$-actin promoter and CMV enhancer. Bicistronic vector was carrying human FGF4 and human VEGF-A genes separated by internal ribosomal entry side (IRES) region under the control of chicken $\beta$-actin promoter and CMV enhancer. IRES of the Polyoma virus 1 origin permitted simultaneous overexpression of both genes. The cDNA for human VEGFA was obtained from pSG5-VEGF-A [24] cloned into the pAAV-MCS. pTR-UF12 and pTR-UF22 were used for cloning of bicistronic plasmid vectors carrying FGF4 and GFP or FGF4 and VEGF-A respectively, and were kindly gifted by Dr Sergei Zolotukhin [25]. cDNA for human FGF4 was subcloned by PCR with appropriate primer pairs from pCAGGS-HST plasmid [26]. 
a
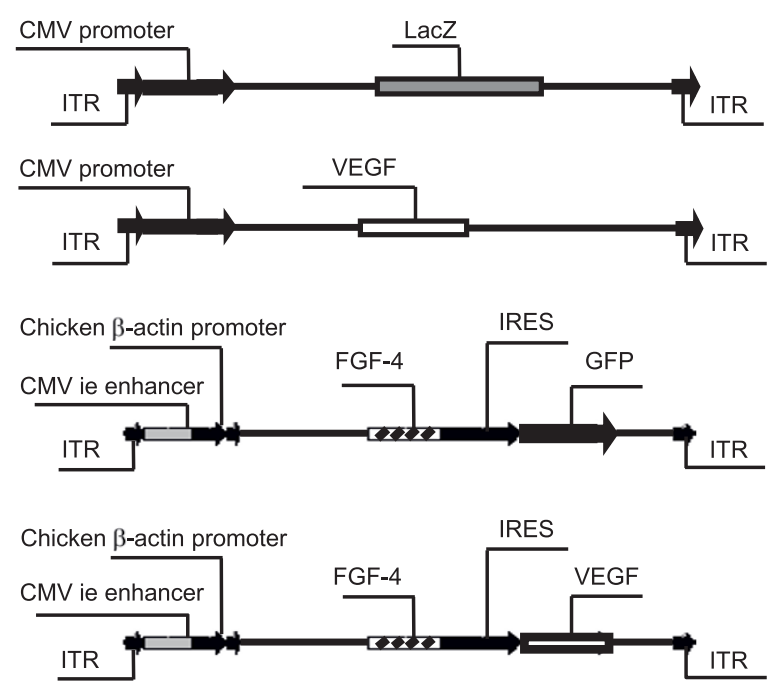

C

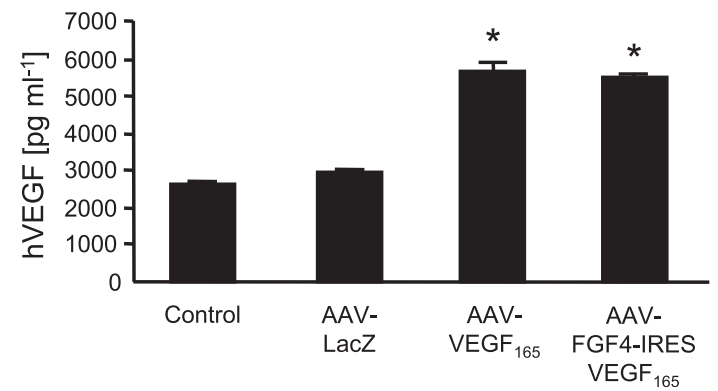

b

AAV-LacZ

${\mathrm{AAV}-V E G F_{165}}$

\section{AAV-FGF4-IRES-GFP}

AAV-FGF4-IRES-VEGF 165

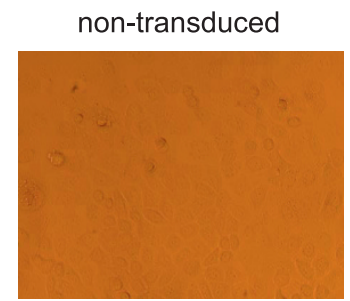

AAV-LacZ

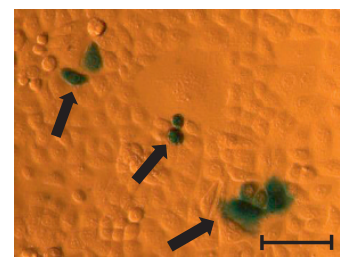

d

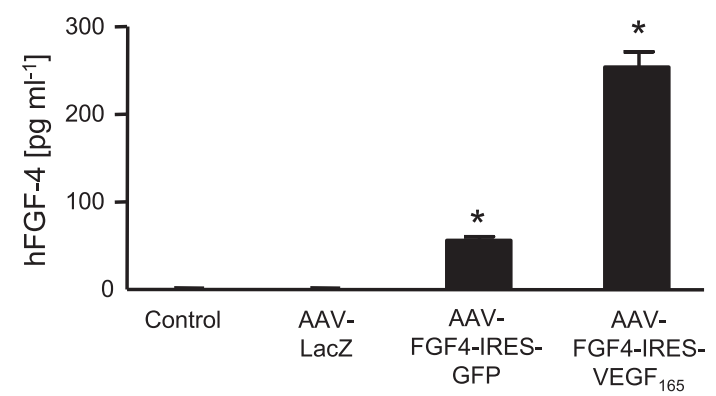

Figure 1 In vitro gene expression in AAV-transduced HeLa cells. (A) Schematic representation of expression cassettes in AAV vectors used for transduction: control vector encoding $\beta$-galactosidase - AAV-LacZ; VEGF-A overexpressing vector - AAV-VEGF-A; FGF4 (cap-dependent cistron) and GFP (IRES-dependent cistron) - AAV-FGF4-IRES-GFP; FGF4 (cap-dependent cistron) and VEGF-A (IRES-dependent cistron) - AAV-FGF4-IRESVEGF-A. CMV ie enhancer - cytomegalovirus immediate-early enhancer. IRES - internal ribosome entry site. (B) $\beta$-galactosidase in situ staining of non-transduced or AAV-LacZ-transduced HeLa cells (arrows). (C) and (D) ELISA determining respectively, hVEGF-A and hFGF4 release into the cell culture media. Production of both hVEGF-A and hFGF4 proteins was significantly up-regulated after transduction with therapeutic vectors when compared to non-transduced (control) cells or cells transduced with AAV-LacZ vector. Representative data out of two independent experiments performed in duplicates. Values are means $\pm S D ;{ }^{*} p<0.05$ vs control and AAV-LacZ. Scale bar $=0.1 \mathrm{~mm}$.

Infectious vector stocks were generated in HEK-293 cells (human embryonic kidney-293 cells), cultured in 150-mm diameter Petri dishes, by co-transfecting each plate with $15 \mu \mathrm{g}$ of each vector plasmid, together with 45 $\mu \mathrm{g}$ of the packaging/helper plasmid pDG (kindly provided by Dr Jurgen A. Kleinschmidt, Program of Infection and Cancer, German Cancer Research Center; Heidelberg, Germany) expressing AAV and adenovirus helper functions. At $12 \mathrm{~h}$ after transfection, the medium was replaced with fresh medium and 3 days later the cells were harvested by scraping, centrifuged and the cell pellets resuspended in $15 \mathrm{ml}$ of $150 \mathrm{mM} \mathrm{NaCl}, 50 \mathrm{mM}$ Tris$\mathrm{HCl}(\mathrm{pH}$ 8.5). Three rounds of fast freeze-thawing were performed on the cell lysate and $50 \mathrm{U} \mathrm{ml}^{-1}$ benzonase was added and incubated for $1 \mathrm{~h}$ at $37^{\circ} \mathrm{C}$. The lysate was then centrifuged at $5000 \mathrm{rpm}$ for $20 \mathrm{~min}$ and supernatant retained and transferred to an Optiseal ultracentrifuge tube (Beckman). An iodixanol gradient was established with 15, 25, 40 and 57\% iodixanol (Optiprep); the 25 and $57 \%$ fractions contained phenol red so that the $40 \%$ fraction, which contained the AAV, was easily visualized. Ultracentrifugation of the gradient was performed in a Beckman ultracentrifuge (rotor type Ti50.2) at $40000 \mathrm{rpm}$ for $2 \mathrm{~h} 40 \mathrm{~min}$ at $18^{\circ} \mathrm{C}$. The $40 \%$ fraction (about $3 \mathrm{ml}$ ) was removed using a 21G needle and applied to a $1 \mathrm{ml}$ Heparin HP column (Amersham Biosciences) connected to the high-performance liquid chromatography (HPLC) system. The column was washed in 
$1 \times$ PBS-MK $(1 \times$ PBS, $1 \mathrm{mM} \mathrm{MgCl} 2,2.5 \mathrm{mM} \mathrm{KCl})$ and virus was eluted in 0-1 $\mathrm{M}$ gradient of $\mathrm{Na}_{2} \mathrm{SO}_{4}$ in $1 \times \mathrm{PBS}$ MK. The viral preparation was desalted by dialysis (Slyde-A-Lyser, Pierce) against $1 \times \mathrm{PBS}$ at $4^{\circ} \mathrm{C}$ and stored at $-80^{\circ} \mathrm{C}$. AAV titer was determined by measuring the copy number of the viral genomes in dialyzed samples. This was achieved by a real-time PCR procedure using primers mapping in the target gene coding region. Primers recognizing LacZ (5'-AGA-ATCCGACGGGTTGTTACTCGC-3' and 5'-TGCGCTCAGGTCAAATTC AGACGGC-3'), hVEGF-A (5'-ATGTCTATCAGCGCAGCTACTGCC-3' and 5'-AGCTCATCTCTCCTATGTGCTGGC-3') and hFGF4 (5'-TGGTGGCGCT CTCGTTGGCG-3' and 5'-ATCGGTGA-AGAAGGGCGAGCC-3') were used. The purified viral preparations used in the present study had particle titers of approx. $1 \times 10^{11}$ viral particles (vp) $\mathrm{ml}^{-1}$. Cells in culture and animals received the dose of AAV stated in the experimental protocol.

\section{Cell culture}

HeLa cells (human epithelial cells from a fatal cervical carcinoma) were maintained in low glucose $(5.5 \mathrm{mM})$ DMEM supplemented with $10 \%$ heat-inactivated FBS, L-glutamine $(2 \mathrm{mM})$, penicillin $\left(100 \mathrm{U} \mathrm{ml}^{-1}\right)$ and streptomycin $\left(10 \mu \mathrm{g} \mathrm{ml}^{-1}\right)$.

Primary isolates of dermal fibroblasts were harvested from 10-week-old diabetic (db/db) C57BLKS mice and their wild-type (WT) littermates. The animals were sacrificed and trunk skin was removed by sharp dissection under sterile conditions. The harvested skin was then minced and digested for 3 hours (from $\mathrm{db} / \mathrm{db}$ mice) and for 6 hours (from WT mice) in $0.2 \%$ collagenase type II (Gibco; Warszawa, Poland) solution in serum-free low glucose DMEM at $37^{\circ} \mathrm{C}$. The dissociated cells were then centrifuged and resuspended in low glucose $(5.5 \mathrm{mM})$ DMEM medium supplemented with $20 \%$ FBS, 2 mM Lglutamine, $100 \mathrm{U} \mathrm{ml}^{-1}$ penicillin, and $10 \mu \mathrm{g} \mathrm{ml}^{-1}$ streptomycin. The cells were cultured at standard conditions: $5 \% \mathrm{CO}_{2}, 37^{\circ} \mathrm{C}$ and humidified atmosphere. After the first or second passage cells from diabetic animals were grown either in low $(5.5 \mathrm{mM})$ or in high $(25 \mathrm{mM})$ glucose concentration for 48-72 hours. Fibroblasts from WT mice were cultured in low glucose DMEM. Cells at passage 2 or 3 were used for experiments.

\section{AAV-mediated transduction of cells in culture}

HeLa cells were cultured at density $1 \times 10^{3}$ per 1 well of the 96-well plate and exposed to $1 \times 10^{3}$ MOI (multiplicity of infection) of AAV-LacZ, AAV-FGF4-IRES-GFP, AAV-VEGF-A and AAV-FGF4-IRES-VEGF-A for 72 hours. After that time the transduction efficiency was determined by $\beta$-galactosidase in situ staining and conditioned culture media were collected for the measurement of therapeutic growth factors production.

\section{Animals}

All animal procedures were in accordance with the declaration of Helsinki and with the Guide for the Care and Use of Laboratory Animals and were approved by the Experimental Animal Committee at the Jagiellonian University. Genetically diabetic C57BLKS mice homozygous for a mutation in the leptin receptor $\left(\operatorname{Lepr}^{\mathrm{db}}\right)$ were obtained from Jackson Laboratories (Bar Harbor, Maine USA). Animals were 14-week-old at the start of the experiments. Diabetic mice were obese, weighing $45 \pm$ $5 \mathrm{~g}$, hyperglycaemic with glucose concentrations in excess of $400 \mathrm{mg}$ per $100 \mathrm{ml}$. The hyperglycaemia produced classic signs of diabetes, including polydipsia, polyuria, and glycosuria. Animals were housed individually, maintained under controlled environmental conditions (12-h light/dark cycle at approx. $23^{\circ} \mathrm{C}$ ), and provided with standard laboratory food and water ad libitum.

\section{Experimental protocol}

After general inhalatory anesthesia with halothane, hair on the back was shaved. Two full-thickness excisional circular wounds (4 $\mathrm{mm}$ in diameter) were made using biopsy punch on the dorsum of each mice. Animals were randomized to receive either PBS, AAV-LacZ, AAV-FGF4-IRES-GFP, AAV-VEGF-A or AAV-FGF4IRES-VEGF-A. Five animals were included into each group $(n=5)$. All AAV vectors and PBS were injected in the wound edges immediately after incision through four (2 per each wound) intradermal injections with a total volume of $100 \mu \mathrm{l}$. Animals received $3 \times 10^{\wedge} 10 \mathrm{vp}$ of an appropriate AAV vector.

\section{Determination of wound area}

Two wounds on the dorsum of each mice were photographed and measured using Image $J$ software by an observer blinded to the experimental protocol at day 0 (directly after wounding), day 1 and then every second day till the end of the observation when the last wounds healed (day 21). Ten wounds per each group were included into the analysis. Wound was considered closed when it was completely covered with epithelium. The wound area measured directly after wounding was used as the reference or original area and all further areas were recorded as the percentage of the original area. Once the experimental schedule was completed (day 21) wounded skin, together with a margin of healthy skin, was excised using $8 \mathrm{~mm}$-diameter biopsy punch. One wound was taken for histological examination ( $\mathrm{n}=5$ /group) and the second one for determination of transgene level or activity ( $n=5$ /group). 


\section{Detection of $\beta$-galactosidase activity}

In situ: PBS- and AAV-LacZ-injected skin was briefly washed in cold PBS, fixed in $2 \%$ buffered formaldehyde and again washed in PBS. AAV-LacZ-transduced cells growing in culture were fixed in $0.25 \%$ buffered formalin and washed in PBS. The samples were immersed overnight in a solution containing $1 \mathrm{mg} \mathrm{ml}^{-1} 5$-bromo-4chloro-3-indolyl- $\beta$-D-galactopyranoside (X-gal), $2 \mathrm{mM}$ $\mathrm{MgCl}_{2}, 5 \mathrm{mM} \mathrm{K}_{3} \mathrm{Fe}(\mathrm{Cn})_{6}, 5 \mathrm{mM} \mathrm{K}_{4} \mathrm{Fe}(\mathrm{Cn})_{6}$ in PBS at $37^{\circ} \mathrm{C}$.

In tissue lysates: $\beta$-galactosidase activity was determined using $\beta$-galactosidase Enzyme Assay in PBS- and AAV-LacZ-injected skin according to vendor's protocol. Activity was normalized to the total protein content and expressed in arbitrary units.

\section{Determination of FGF4 and VEGF-A protein by ELISA}

Skin samples were homogenized in $300 \mu \mathrm{l}$ of lysis buffer (PBS with 1\% Triton and protease inhibitors - $10 \mathrm{mM}$ PMSF, $1 \mathrm{mg} \mathrm{ml}^{-1}$ aprotinin and $1 \mathrm{mg} \mathrm{ml}^{-1}$ leupeptin) using an TissueLyser homogenizer (Qiagen). The homogenate was centrifuged at $21000 \mathrm{~g}$ for $10 \mathrm{~min}$ at $4^{\circ} \mathrm{C}$. The supernatant was collected and used for protein determination using the Bicinchoninic Acid Protein Assay Kit. Analysis was performed with hFGF4- and hVEGF-A-recognizing ELISA kits. The level of hFGF4 and hVEGF-A in conditioned culture medium of AAVtransduced HeLa cells was determined with the same ELISA reagents. The amount of hFGF4 and hVEGF-A was expressed in $\mathrm{pg} / \mathrm{mg}$ protein (when determined in tissue lysates) and in $\mathrm{pg} \mathrm{ml}^{-1}$ (when determined in conditioned cell culture media).

\section{Histology}

Skin from the healed wound beds surrounded by a margin of normal skin and the underlying muscle layer were harvested and fixed in $10 \%$ neutral buffered formalin for at least $24 \mathrm{~h}$ at room temperature, dehydrated in graded ethanol, cleared in xylene and embedded in paraffin. Perpendicular sections to the anterior posterior axis of the wounds ( $3 \mu \mathrm{m}$ thick) were mounted on glass slides, dewaxed, rehydrated with distilled water and stained with haematoxylin/eosin or with Masson's trichrome, according to routine procedures for light microscopy. The areas proximal to the incision were evaluated in all skin sections in 10 random microscopic fields (1000x magnification) by an observer blinded to the experimental protocol. The following parameters were evaluated and scored as previously described [27,28], modified and internally validated in our laboratory: 1) vascularity, 2) granulation tissue formation and remodeling and 3) dermal matrix deposition and regeneration. We used fourpoint scale to evaluate vascularity (1 - one or two vessels per site; 2 - three vessels per site; 3 - four vessels per site; 4 - five or more vessels per site) and three-point scale to evaluate granulation tissue formation ( 1 - thin granulation layer with up to 35 cells per site; 2 - moderate granulation layer with up to 45 cells per site; 3 thick granulation layer with up to 55 and more cells per site) and dermal matrix deposition and regeneration (1 little collagen deposition and little regeneration with up to 10 hair follicles within the scar; 2 - moderate collagen deposition and moderate regeneration with up to 20 hair follicles within the scar; 3 - high collagen deposition and complete regeneration with up to 30 and more hair follicles within the scar). The edges of the wound in each of the sections were used as comparisons for scoring.

\section{Immunohistochemistry}

To visualize the smallest blood vessels $(<10 \mu \mathrm{m}$ of the inner diameter), skin sections were deparaffinized and subjected to antigen retrieval using $0.05 \mathrm{M}$ sodium citrate buffer ( $\mathrm{pH}$ 6.0). Capillary endothelial cells were detected with biotinylated Bandeiraea simplicifolia I (BS-I) isolectin $\mathrm{B}_{4}$ (dilution 1:100, Vector Laboratories; Janki, Poland). Incorporated isolectin was detected with streptavidin- and fluorochrome-conjugated antibodies (Streptavidin Alexa Fluor 546). Additionally, in order to visualize endothelial cell proliferation tissue sections were exposed to proliferating cell nuclear antigen (PCNA) recognizing antibodies (dilution 1:200) followed by fluorochrome-conjugated secondary antibodies (Alexa Fluor 488). All sections were mounted in DAPI (4',6-diamidino-2-phenylindole)-containing medium (a fluorescent stain that strongly binds to DNA).

\section{Proliferation assay}

Mouse dermal fibroblasts were seeded in 96-well plate at confluence $3 \times 10^{3}$ cells per well and grown in complete DMEM medium containing low $(5.5 \mathrm{mM})$ glucose (cells from WT and $\mathrm{db} / \mathrm{db}$ mice) or high $(25 \mathrm{mM})$ glucose (cells from $\mathrm{db} / \mathrm{db}$ mice) for 24 hours. One hour before stimulation complete medium was removed and cells were overlaid with medium containing 0.5\% FBS. Cells were stimulated either with rhVEGF-A $\left(50 \mathrm{ng} \mathrm{ml}^{-1}\right)$ or rhFGF4 (50 $\mathrm{ng} \mathrm{ml}^{-1}$ ) or with both (50 $\mathrm{ng} \mathrm{ml}^{-1}$ each) for 24 hours. BrdU incorporation assay was performed according to vendor's protocol.

\section{Migration assay}

Transwell plates ( $8 \mu \mathrm{m}$ pore) (Costar, Corning; Poznan, Poland) were coated with fibronectin $\left(20 \mu \mathrm{g} \mathrm{ml}^{-1}\right)$ mixed with $0.5 \%$ gelatin in $1: 1$ ratio. Cells $\left(1 \times 10^{4}\right.$ per transwell) resuspended in DMEM medium containing low (5.5 $\mathrm{mM}$ ) glucose (WT and $\mathrm{db} / \mathrm{db}$ fibroblasts) or high 
(25 mM) glucose (db/db fibroblasts) supplemented with $0.5 \%$ bovine serum albumin (BSA) were applied on the coated transwell plates (upper compartment of a Boyden chamber). Transwell plates with cells were then placed in wells of a 24-well culture dish filled either with low (5.5 mM) glucose (WT and $\mathrm{db} / \mathrm{db}$ fibroblasts) or high (25 mM) glucose (db/db fibroblasts) DMEM containing 0.5\% BSA supplemented either with rhVEGF-A (50 ng $\mathrm{ml}^{-1}$ ) or rhFGF4 $\left(50 \mathrm{ng} \mathrm{ml}^{-1}\right)$ or with both $\left(50 \mathrm{ng} \mathrm{ml}^{-1}\right.$ each) (lower compartment of a Boyden chamber). After 20 hours of culture at $37^{\circ} \mathrm{C}$ each of the transwell plates was washed with PBS, fixed in $10 \%$ formalin and stained with haematoxylin and eosin. The non-migratory cells from the filter surface of the upper compartment were gently removed and only the cells that migrated to the lower side were counted in 4 random microscopic fields (200× magnification).

\section{Quantitative RT-PCR}

Total RNA was isolated from cells with Fenozol Total RNA Isolation Reagent (PAA). Synthesis of cDNA was performed using oligo-dT primers for $1 \mathrm{~h}$ at $42^{\circ} \mathrm{C}$ using MMLV reverse transcriptase, according to vendor's instruction. Quantitative RT-PCR was performed in a Rotor Gene RG-3000 (Corbett Research) in a mixture containing SYBR Green PCR Master Mix (SYBR Green qPCR Kit), $50 \mathrm{ng}$ of cDNA and specific primers in a total volume of $15 \mu \mathrm{l}$. The primers recognizing MMP-9 (5' - TGTGGATGTTTTTGATGCTATTG-3' and 5' CGGAGTCCAGCGTTGCA-3'), Flt-1 (5'-GCACCTATGCSTGCAGAGC- $3^{\prime}$ and $5^{\prime}$-TCTTTCAATAAACAGCGTGCTG-3') and EF2 (5'-GCGGTCAGCACA ATGGCATA and 5'-GACATCACCAAGGGTGTGCAG-3') were used. EF2 (elongation factor 2) was used as a housekeeping gene. After incubation for $15 \mathrm{~min}$ at $95^{\circ} \mathrm{C}$, a three-step cycling protocol $\left(30 \mathrm{~s}\right.$ at $95^{\circ} \mathrm{C}, 45 \mathrm{~s}$ at $60^{\circ} \mathrm{C}$ and $45 \mathrm{~s}$ at $72^{\circ} \mathrm{C}$ ) was used for 40 cycles. The melting curve analysis was done using the program supplied by Corbett Research. Relative quantification of gene expression was calculated based on the comparative $C_{T}$ (threshold cycle value) method $\left(\Delta C_{T}=C_{T}\right.$ gene of interest $-C_{T}$ housekeeping gene). Comparison of gene expression in different samples was performed basing on the differences in $\Delta C_{T}$ of individual samples $\left(\Delta \Delta C_{T}\right)$.

\section{Statistical analysis}

Results are expressed as mean \pm SEM unless otherwise stated. One-way analysis of variance (ANOVA) followed by Bonferroni's post-hoc test or unpaired Student's t-test was used to evaluate the statistical significance between investigated groups. $\mathrm{p}<0.05$ was considered statistically significant.

\section{Results}

VEGF-A and FGF4 are efficiently produced by

AAV-transduced HeLa cells

HeLa cells were exposed to AAV-LacZ, AAV-VEGF-A, AAV-FGF4-IRES-GFP, and AAV-FGF4-IRES-VEGF-A vectors (Figure 1a) each of them administered at $1 \times$ $10^{3}$ MOI. This dose of vectors did not influence the cell viability (data not shown). The analysis of gene expression was performed $72 \mathrm{~h}$ after transduction. As judged from LacZ staining (Figure 1b) the in vitro transduction efficiency with this dose of vectors was not very potent (about 3.5\%) but high enough to see the overexpression of all introduced genes (Figure 1b, c, d). Since VEGF-A and FGF4 are secreted proteins [6,21], their expression was measured by ELISA in the culture supernatants collected from transduced and non-transduced HeLa cells (Figure 1c and 1d, respectively). In adults, FGF4 is produced only under pathological conditions by certain cancer cells, while HeLa cell line has been characterized as non-expressing FGF4 [29]. In our hands, control (non-transduced and AAV-LacZ-transduced) HeLa cells also did not release FGF4 into the cell culture media (Figure 1d), while they release about $2616 \pm 48 \mathrm{pg} \mathrm{ml}^{-1}$ of human VEGF-A (Figure 1c). Transduction with control vector (AAV-LacZ) did not significantly affect this production which was about $2916 \pm 50 \mathrm{pg} \mathrm{ml}^{-1}$ (Figure 1c). When AAV-VEGF-A or AAV-FGF4-IRESVEGF-A were added to the cells the production of VEGF increased about 2-fold - up to $5667 \pm 165 \mathrm{pg} \mathrm{ml}^{-1}$ and $5471 \pm 34 \mathrm{pg} \mathrm{ml}^{-1}$, respectively (Figure 1c). Interestingly, the localization of hVEGF-A gene after CMV or IRES sequence in the vector did not influence this protein production, as in both cases it was comparable. Unlike hVEGF-A, hFGF4 production was much lower and reached $56 \pm 4 \mathrm{pg} \mathrm{ml}^{-1}$ and $254 \pm 17 \mathrm{pg} \mathrm{ml}^{-1}$ after transduction with AAV-FGF4-IRES-GFP and AAV-FGF4-IRES-VEGF-A, respectively (Figure 1d). The experiments revealed that both VEGF-A and FGF-4 were released from the cells (data not shown) what confirmed previously published observations [21].

\section{Wound closure is significantly accelerated after AAV- VEGF-A and AAV-FGF4-IRES-VEGF-A administration}

Mice homozygous for a mutation in the leptin receptor $\left(\right.$ Lepr $\left.^{\mathrm{db}}\right)$ exhibit a phenotype similar to adult-onset diabetes mellitus (type II), including a significant woundhealing impairment when compared with their nondiabetic littermates [30,31]. In this study, a 4-mm full-thickness excisional wound model was used. Animals were randomized to receive either PBS, AAV-LacZ, AAV-FGF4-IRES-GFP, AAV-VEGF-A or AAV-FGF4IRES-VEGF-A (see Figure 1a). Although one of the 
vectors (AAV-FGF4-IRES-GFP) expressed two proteins therapeutic (FGF4) and control (GFP) we decided to use additional $\beta$-galactosidase (LacZ) expressing vector as the most appropriate control for our study. First of all, LacZ was shown to be less immunogenic than GFP [32]. This seems to be of great importance in wound healing studies as prolonged and dysregulated inflammatory phase results in poor healing [33]. Moreover, IRESdependent gene expression in bicistronic vectors was shown to be lower than cap-dependent gene expression [25]. Since our therapeutic genes were mostly capdependent (except VEGF-A in AAV-FGF4-IRES-VEGF$A$ vector) we decided to use a control vector carrying LacZ gene under the strong constitutive CMV promoter. Additionally, presence of GFP sequence in AAV-FGF4IRES-GFP vector served as a control for VEGF-A used in the second AAV-FGF4-IRES-VEGF-A bicistronic vector.

The lesions were analyzed at different time-points by measuring the wound area. Neither AAV-LacZ nor AAV-FGF4-IRES-GFP accelerated wound closure at any stage of the healing process (Figure 2a). In late stages of the healing process wounds treated either with AAVVEGF-A or AAV-FGF4-IRES-VEGF-A healed significantly faster confirming a crucial role of VEGF-A in this phenomenon (Figure 2a). The reduction of the wound area after AAV-VEGF-A injection was clearly visible starting from day $17: 3.48 \pm 1.47 \%$ of the initial wound area vs $9.87 \pm 4.95 \%$ in PBS group $(\mathrm{p}<0.05)$ and vs $12.5 \pm 4.05 \%$ in AAV-LacZ group $(\mathrm{p}<0.05)$. At day 19 all wounds in AAV-VEGF-A group were covered with epithelium and considered closed (Figure 2a, b). Interestingly, the reduction of the wound area after AAVFGF4-IRES-VEGF-A injection was even more potent starting already from day 13: $14.49 \pm 3.29 \%$ of the initial wound area vs $26.65 \pm 0.16 \%$ in PBS group $(\mathrm{p}<0.05)$ and vs $25.7 \pm 2.37 \%$ in AAV-LacZ group $(\mathrm{p}<0.05)$ at day $13 ; 6.86 \pm 2.75 \%$ of the initial wound area vs $19.35 \pm 3.07 \%$ in PBS group $(\mathrm{p}<0.05)$ and vs $16.42 \pm$ $3.2 \%$ in AAV-LacZ group ( $\mathrm{p}<0.05$ ) at day 15. At day 17 all wounds in AAV-FGF4-IRES-VEGF-A group were covered with epithelium and considered closed. The healing process in some animals from PBS, AAV-LacZ as well as AAV-FGF4-IRES-GFP groups was prolonged until day 21 (Figure 2a).

\section{Transgene expression in wounds of $\mathrm{db} / \mathrm{db}$ mice 21 days after AAV transduction}

To study the location and the time course of AAV expression in wounds $\beta$-galactosidase activity was determined by histological analysis and using colorimetric assay in skin lysates of AAV-LacZ injected mice 21 days after treatment. Skin samples from PBS group served as negative controls. Local $\beta$-galactosidase activity was observed in histological skin sections close to the sites of wounding and gene transfer. The blue staining was present mostly in the dermal layer and hair follicles (Figure 3a). The colorimetric assay in tissue lysates indicated weak statistically not significant increase in the $\beta$-galactosidase activity when compared to the PBS injected animals (Figure 3b).

Expression of both therapeutic genes in skin lysates was determined at day 21 using ELISA kits recognizing hVEGF-A and hFGF4 proteins (Figure 3c, d). Slight increase in the level of hVEGF was detected after AAVVEGF-A administration $(1.7 \pm 1.22 \mathrm{pg} / \mathrm{mg}$ protein $)$ (Figure 3c). hVEGF protein was not detected in the skin of AAV-FGF4-IRES-VEGF-A-injected mice with available ELISA kit (Figure 3c). In case of hFGF4 its level in skin homogenates of diabetic mice after AAV-FGF4IRES-GFP injection was a bit higher $(5.66 \pm 1.27 \mathrm{pg} / \mathrm{mg}$ protein) than after AAV-FGF4-IRES-VEGF-A (1.94 \pm $0.84 \mathrm{pg} \mathrm{mg}^{-1}$ protein) (Figure $3 \mathrm{~d}$ ). Of note, despite the higher production of hFGF4 from AAV-FGF4-IRESGFP, the acceleration of wound healing was faster in mice receiving AAV-FGF4-IRES-VEGF-A, indicating for the significance of combined growth factors delivery.

\section{Local AAV-FGF4-IRES-VEGF-A delivery promotes wound healing at the histological level}

Diabetic animals usually have a thicker epithelial layer than normal mice [27]. In addition, the different layers are less differentiated and adipose infiltrates are present in the dermis, impairing the normal elasticity of the skin and, as a consequence, it is more prone to a delayed healing [27]. At day 21 all wounds were already covered with epithelium therefore, by histological evaluation, we were not able to observe any differences in the grade of re-epithelialization between analyzed groups of animals. Nevertheless, the epithelial layer covering AAV-VEGFA- and AAV-FGF4-IRES-VEGF-A-treated wounds was thicker and had a greater cell density when compared to PBS or AAV-LacZ controls or AAV-FGF4-IRES-GFPtreated wounds (Figure 4a, b, photos IV and V).

Interestingly, within the scar tissue of most of the analyzed skin sections we found clusters of inflammatory cells forming granulomas (Figure 4a, photo VI). Granuloma represents a special type of inflammatory reaction in which collection of immune cells is trying to destroy a foreign substance. Apparently, this immune response does not seem to be related to any of the introduced transgenes or AAV capsid proteins as granulomas were found within the healed wounds of all investigated groups of animals including mice injected with PBS. The real cause of such inflammatory reaction is not known and we presume that it might be related to wounding-induced cholesterol crystals formation. 
a

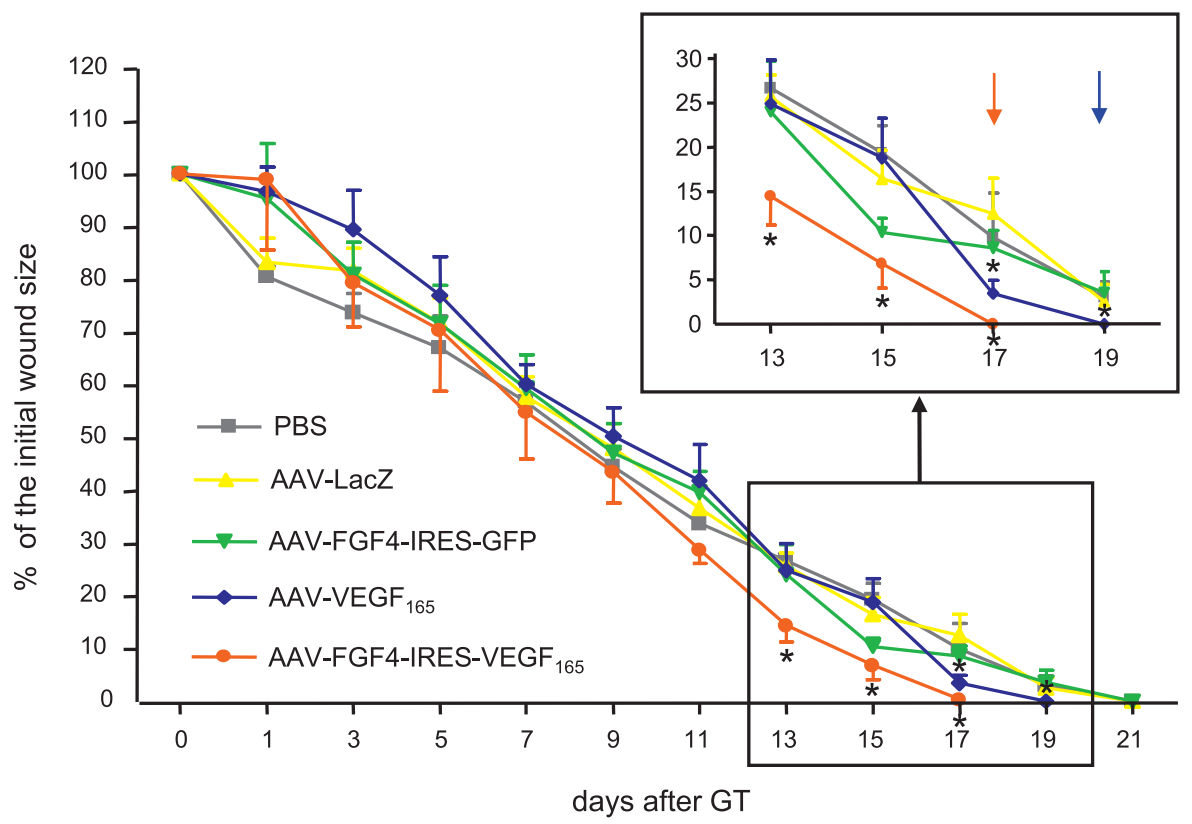

b

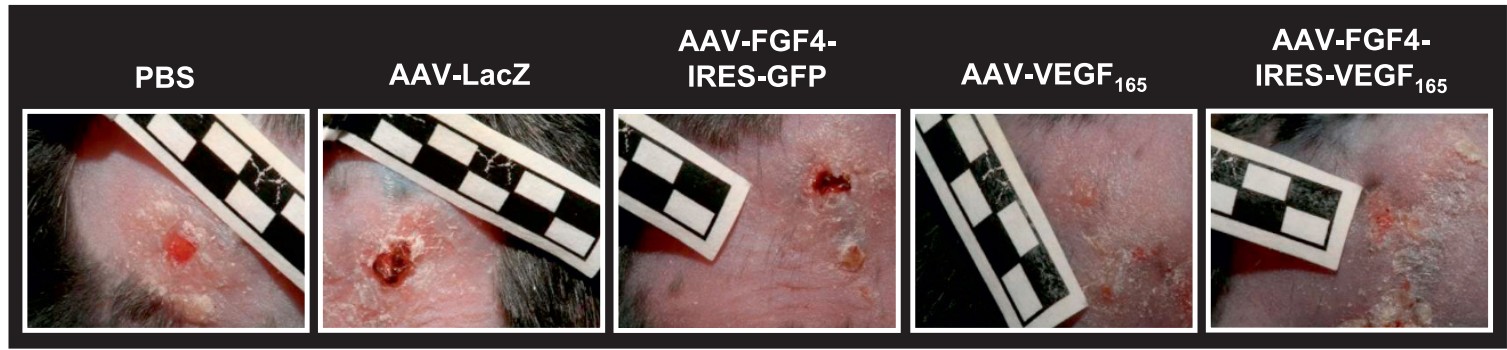

Figure 2 AAV-VEGF-A and AAV-FGF4-IRES-VEGF-A accelerates time to wound closure in $\mathbf{d b} / \mathbf{d b}$ mice. (A) Quantification of the wound area at consecutive days. Reduction of the wound area after AAV-VEGF-A injection was significantly enhanced starting from day 17 . At day 19 all wounds in AAV-VEGF-A group were covered with epithelium and considered closed (arrow, inset). The reduction of the wound area after AAVFGF4-IRES-VEGF-A injection was even more visible when compared to AAV-LacZ-injected controls starting already from day 13 . At day 17 all wounds in AAV-FGF4-IRES-VEGF-A group were covered with epithelium and considered closed (arrow, inset). No acceleration of the wound closure was observed after AAV-FGF4-IRES-GFP at any time-point and the last wounds in this group were considered closed at day 21 together with PBS- and AAV-LacZ-injected animals. (B) Representative pictures taken at day 19 showing wounds of AAV-VEGF-A and AAV-FGF4-IRES-VEGFA-injected animals completely covered with epithelium and prolonged healing process in PBS-, AAV-LacZ- and AAV-FGF4-IRES-GFP-treated mice. Graph represents means \pm SEM ( $n=10$ wounds/group); ${ }^{*} p<0.05$ vs PBS and AAV-LacZ.

Although, plenty of inflammatory cells could still be found in the skin sections, most of the cells within the scar tissue of all analyzed groups were of mesenchymal origin (fibroblasts and myofibroblasts). It indicates that the process of tissue remodeling has already been initiated. Granulation tissue and especially its vascularity was enhanced after all three therapeutic vectors in comparison to the control PBS- and AAV-LacZ-injected animals however, statistically significant difference was observed only after bicistronic AAV-FGF4-IRES-VEGF$A$ vector administration (Figure $5 \mathrm{a}$ and $5 \mathrm{~b}$, respectively). Thus, VEGF-A delivered in combination with FGF4 into the wound edge reduced adipose substitution and produced a significant improvement in the healing process by increasing the thickness and vascularization of granulation tissue. Additionally, single (AAV-FGF4IRES-GFP and AAV-VEGF-A) or combined (AAVFGF4-IRES-VEGF-A) gene transfer resulted in abundant collagen deposition in comparison to the PBS- or AAVLacZ-treated control wounds (Figure 5c).

\section{AAV-VEGF-A stimulates new blood vessels formation in the skin of $\mathrm{db} / \mathrm{db}$ mice}

Isolectin $\mathrm{B}_{4}$ was used to visualize the smallest blood vessels (capillaries) in the skin tissue 21 days after wounding and gene transfer (Figure 6a). Double immunofluorescent 
a

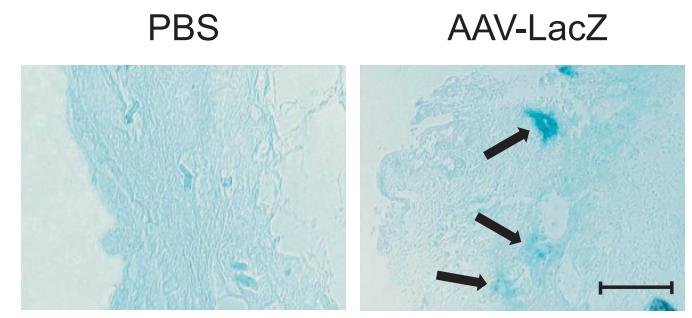

C

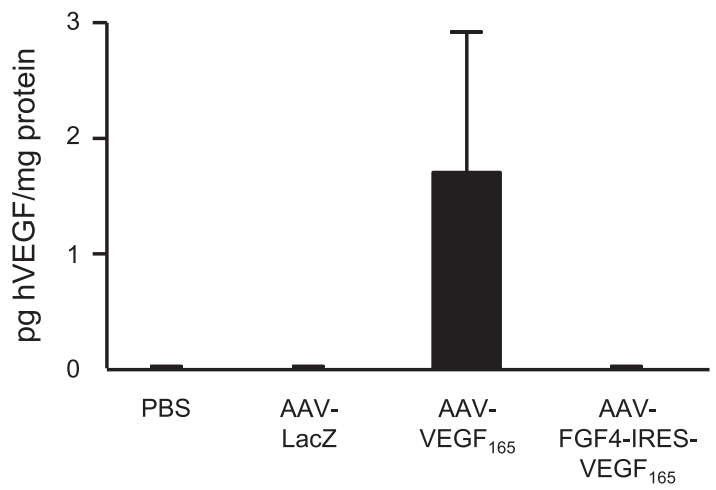

b

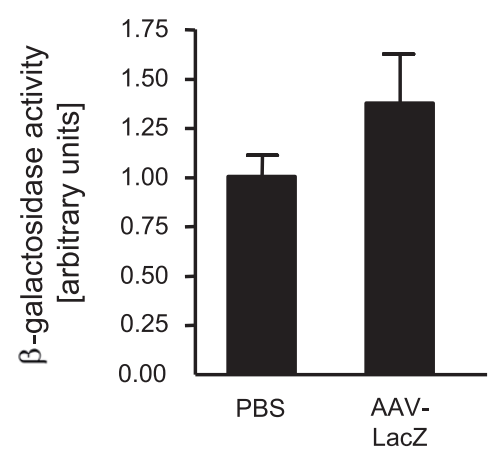

d

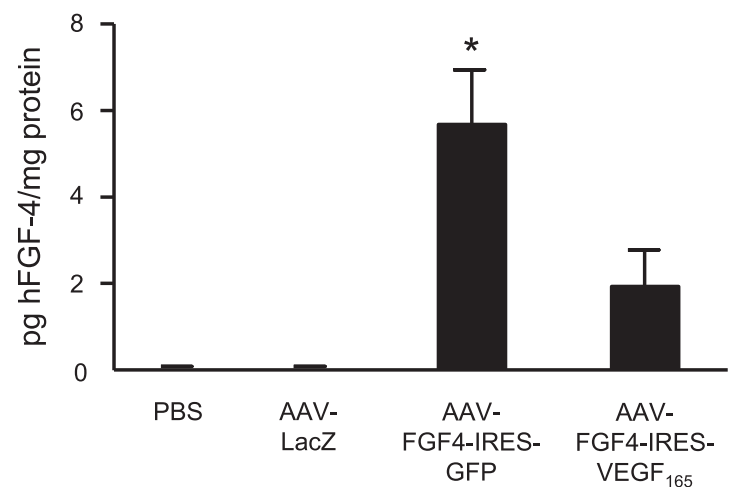

Figure 3 Weak transgene expression in the skin of $\mathbf{d b} / \mathbf{d b}$ mice 21 days after wounding and gene transfer. (A) Representative skin sections demonstrating $\beta$-galactosidase activity (arrows) in AAV-LacZ injected animal and the negative control (PBS treated skin). (B) Colorimetric assay showing slightly increased $\beta$-galactosidase activity in skin tissue homogenates from AAV-LacZ-injected animlas in comparison to the PBStreated mice. (C) hVEGF and (D) hFGF4 protein in skin tissue homogenates measured by ELISA. Graphs represent means \pm SEM ( $n=5$ animals/ group); ${ }^{*} p<0.05$ vs PBS and AAV-LacZ. Scale bar $=0.05 \mathrm{~mm}$.

staining using biotinylated isolectin $\mathrm{B}_{4}$ and PCNA-recognizing antibodies revealed that administration of AAVVEGF-A stimulated angiogenesis by induction of proliferation of capillary endothelial cells in the dermal area proximal to the healed incision $\left(10.2 \pm 1.06 / \mathrm{mm}^{2}\right.$ vs $4.77 \pm 1.77 / \mathrm{mm}^{2}$ in PBS group; $\mathrm{p}<0.05$ and vs $5.31 \pm$ $0.8 / \mathrm{mm}^{2}$ in AAV-LacZ group; $\mathrm{p}<0.05$ ) (Figure $6 \mathrm{~b}$ ). This was paralleled with increased total number of capillaries $\left(42.47 \pm 1.37 / \mathrm{mm}^{2}\right.$ vs $33.5 \pm 2.7 / \mathrm{mm}^{2}$ in PBS group; $\mathrm{p}<0.05$ and vs $35.41 \pm 2.9 / \mathrm{mm}^{2}$ in AAV-LacZ group; $\mathrm{p}=0.09$ ) (Figure $6 \mathrm{c}$ ). The number of skin capillaries detected 21 days after wounding and AAV-FGF4-IRESGFP or AAV-FGF4-IRES-VEGF-A injection did not differ significantly from PBS- and AAV-LacZ-treated animals (Figure 6c).

\section{In vitro characteristics of healthy (WT) and diabetic (db/} db) mouse dermal fibroblasts

Our observation that AAV-FGF4-IRES-VEGF-A and $A A V-V E G F-A$ accelerated time to wound closure in mice prompted us to explore the underlying mechanisms.
As the efficiency of growth factors in vivo could result from sustained production by AAV vector which occurred during entire healing process and would require much more animals to check in details, we decided to investigate the migratory and proliferation capabilities of fibroblasts using recombinant growth factors.

Proliferation of diabetic and wild-type fibroblasts was measured using BrdU incorporation assay (Figure 7a). Diabetic fibroblasts cultured in low glucose $(5.5 \mathrm{mM})$ DMEM proliferated slightly but significantly slower than wild-type cells $(81.5 \pm 7.4 \%$ vs $100 \%$, respectively; $\mathrm{p}<0.05)$. Fibroblasts from diabetic mice cultured in high glucose (25 mM) DMEM exhibited more potent reduction in proliferation rate $(61.5 \pm 13 \%$ vs $100 \%$ in WT control; $\mathrm{p}<0.05$ and vs $81.5 \pm 7.4 \%$ in $\mathrm{db} / \mathrm{db}$ $5.5 \mathrm{mM}$ control; $\mathrm{p}<0.05)$. rhFGF4 delivered alone or in combination with rhVEGF significantly increased the proliferation of wild-type fibroblasts $(133.7 \pm 19.2 \%$ and $121.8 \pm 20.6 \%$ vs $100 \%$ WT control, respectively). Proliferation of $\mathrm{db} / \mathrm{db}$ fibroblasts cultured in low glucose in the presence of rhFGF4 was slightly weaker than of WT 
a
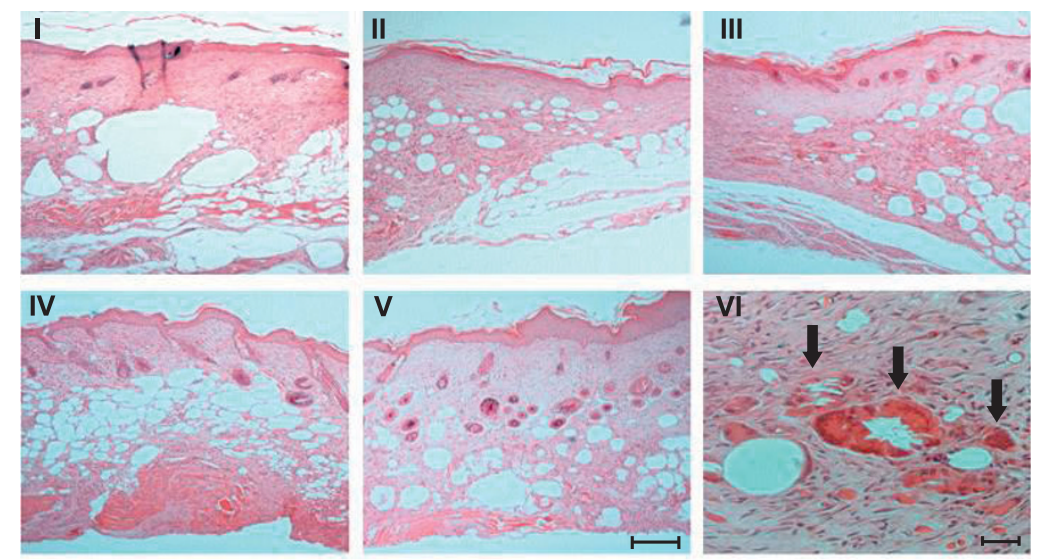

b
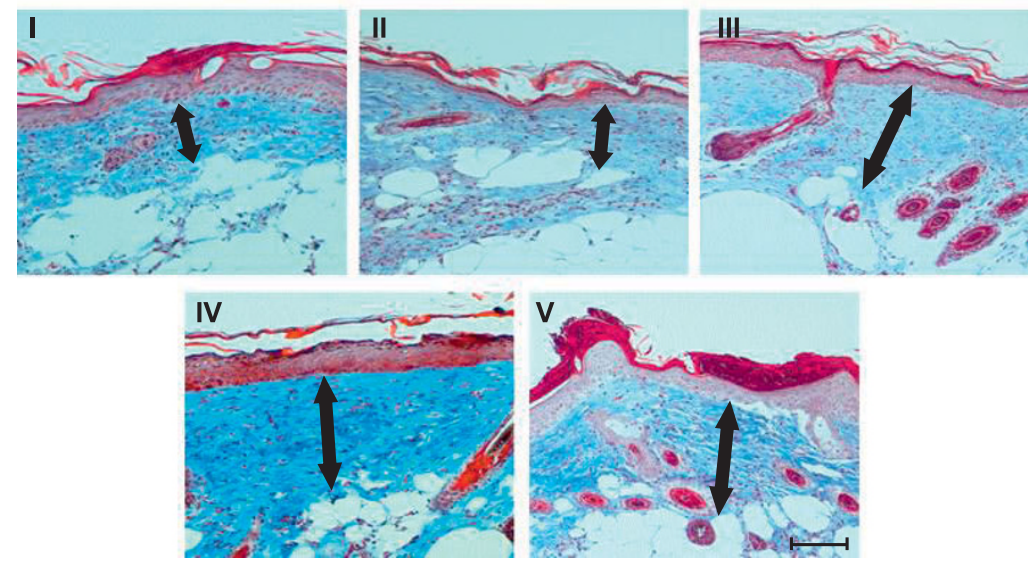

Figure 4 Skin morphology of $\mathbf{d b} / \mathbf{d b}$ mice 21 days after wounding and gene transfer. (A) Haematoxylin/eosin staining of the skin injected with (I) PBS; (II) AAV-LacZ; (III) AAV-FGF4-IRES-GFP; (IV) AAV-VEGF-A and (V) AAV-FGF4-IRES-VEGF-A. Analysis revealed less adipose tissue and better organized granulation tissue with the presence of hair and restoration of normal architecture of dermis in AAV-VEGF-A and AAV-FGF4IRES-VEGF-A-treated mice in comparison to PBS-, AAV-LacZ- and AAV-FGF4-IRES-GFP-injected animals. Panels are representative of 5 animals per group. Scale bar $(I-V)=0.1 \mathrm{~mm}$. (VI) Higher magnification of AAV-FGF4-IRES-VEGF-A-injected skin with granulomas (arrows). Scale bar (VI) $=0.05$ mm. (B) Representative Masson's trichrome staining of the skin injected with (I) PBS; (II) AAV-LacZ; (III) AAV-FGF4-IRES-GFP; (IV) AAV-VEGF-A and (V) AAV-FGF4-IRES-VEGF-A. Double-headed arrows indicate the thickness of the collagen layer that was significantly thicker after injection of all three therapeutic vectors (AAV-FGF4-IRES-GFP, AAV-VEGF-A, AAV-FGF4-IRES-VEGF-A) when compared to PBS- and AAV-LacZ-treated animals. Panels are representative of 5 animals/group. Scale bar $=0.05 \mathrm{~mm}$.

cells and, although the trend was clearly visible, did not reach the statistical significance $(103.5 \pm 6.3 \%$ vs $81.5 \pm$ $7.4 \% \mathrm{db} / \mathrm{db} 5.5 \mathrm{mM}$ control, $\mathrm{p}=0.09$ ) (Figure 7a). Interestingly, combined rhFGF4 and rhVEGF-A treatment slightly but significantly increased the proliferation rate of $\mathrm{db} / \mathrm{db}$ fibroblasts cultured in low glucose $(115 \pm 6.4 \%$ vs $81.5 \pm 7.4 \% \mathrm{db} / \mathrm{db} 5.5 \mathrm{mM}$ control, $\mathrm{p}<0.05)$. Cells from $\mathrm{db} / \mathrm{db}$ mice cultured in high glucose concentration did respond neither to rhFGF4 or rhVEGF-A and their proliferation did not change significantly when two growth factors, rhFGF4 and rhVEGF-A, were used (Figure 7a).

Differences in basal migration on fibronectin/gelatin were observed between diabetic $(\mathrm{db} / \mathrm{db})$ and healthy (WT) fibroblasts (Figure 7b). Migration of diabetic fibroblasts cultured in low glucose DMEM was impaired when compared to wild-type fibroblasts $(73.5 \pm 7 \%$ vs $100 \%$, respectively; $\mathrm{p}<0.05$ ). When diabetic fibroblasts were cultured in high glucose DMEM the impairment of migration was much more potent $(49 \pm 13 \%$ vs $100 \%$ in WT control; $\mathrm{p}<0.05$ and vs $73.5 \pm 7 \%$ in $\mathrm{db} / \mathrm{db}$ $5.5 \mathrm{mM}$ control; $\mathrm{p}<0.05)$. Migration in response to single rhFGF4 treatment increased more than 2 times in case of wild-type fibroblasts $(249.7 \pm 19 \%$; $\mathrm{p}<0.05$ vs WT control) and about 3 times in case of diabetic fibroblasts cultured in low glucose DMEM (313.5 $\pm 87.4 \%$; $\mathrm{p}<0.05 \mathrm{vs} \mathrm{db} / \mathrm{db} 5.5 \mathrm{mM}$ control). When rhFGF4 was added in combination with rhVEGF-A the migration of both cell types (WT and $\mathrm{db} / \mathrm{db}$ cultured in low glucose) did not differ significantly from the one observed after 


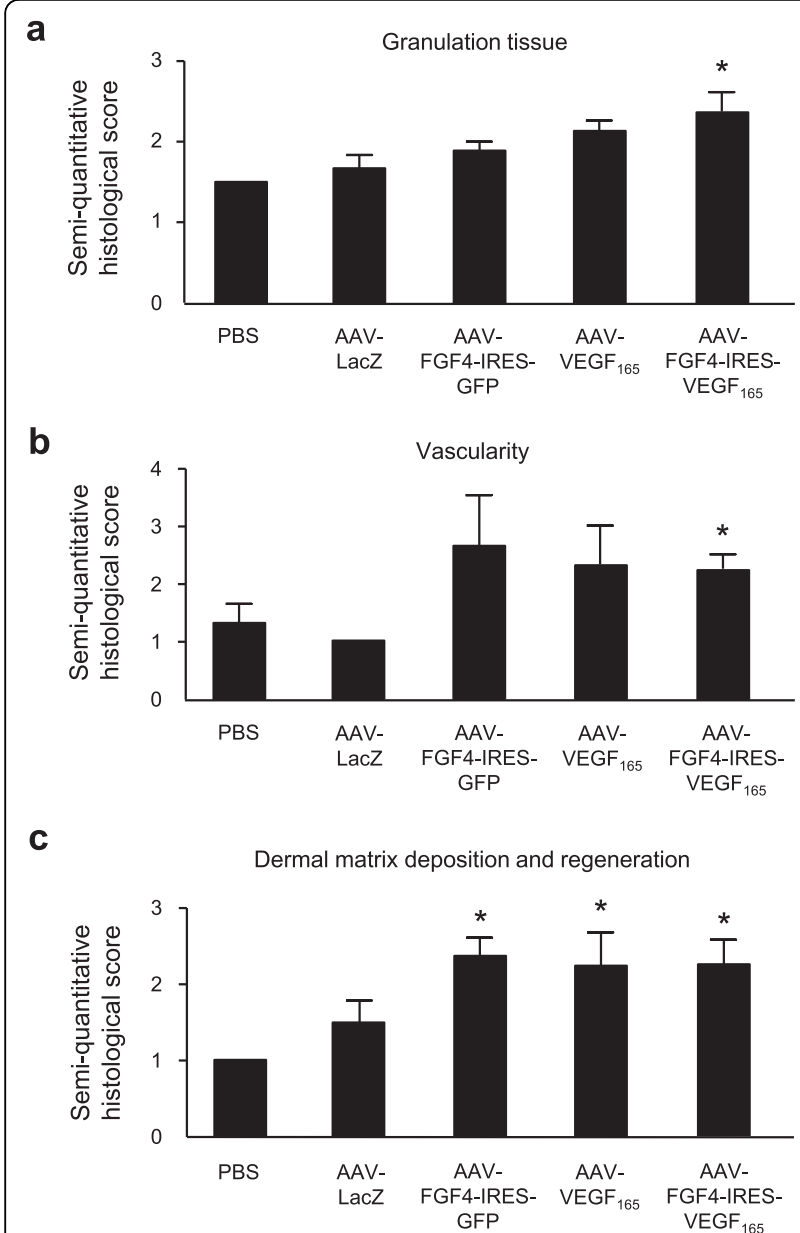

Figure 5 Semi-quantitative evaluation for granulation tissue: (A) granulation tissue, (B) vascularity, and (C) dermal matrix deposition and regeneration. Graphs represent means \pm SEM ( $n=5$ animals/group); ${ }^{*} p<0.05$ vs PBS and AAV-LacZ.

single rhFGF4 treatment $(264 \pm 64 \%$; $<0.05$ vs WT control and $419.4 \pm 192.7 \%$ vs db/db $5.5 \mathrm{mM}$ control, respectively) (Figure $7 \mathrm{~b})$. Migration of diabetic fibroblasts cultured in high glucose DMEM did change neither upon single rhFGF4 nor rhVEGF-A treatment. However, it was strongly increased (about 4 times) in response to both growth factors $(196.4 \pm 60.4 \%, \mathrm{p}<$ $0.05 \mathrm{vs} \mathrm{db/db} 25 \mathrm{mM}$ control) (Figure $7 \mathrm{~b}$ ).

\section{FGF4 stimulates MMP-9 and Flt-1 expression in primary mouse dermal fibroblasts}

Basal MMP-9 expression did not differ significantly between analyzed groups (Figure 8a). Sole rhVEGF-A treatment did not influence MMP-9 expression in diabetic dermal fibroblasts cultured in high glucose concentration (Figure 8b), but it was significantly upregulated by rhFGF4 (Figure $8 \mathrm{~b}$ ). As there was no additional up-regulation after combined rhFGF4 and a

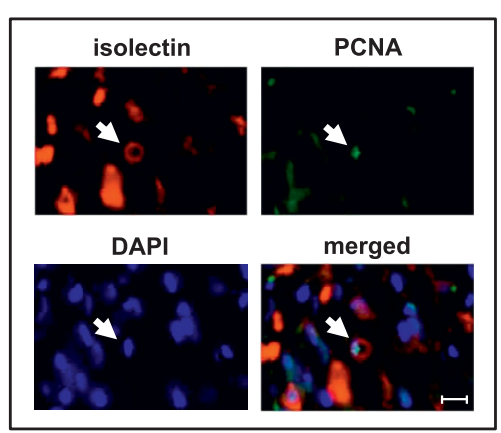

b

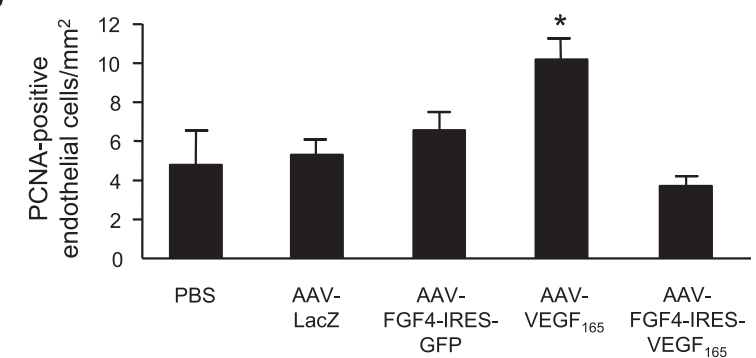

C

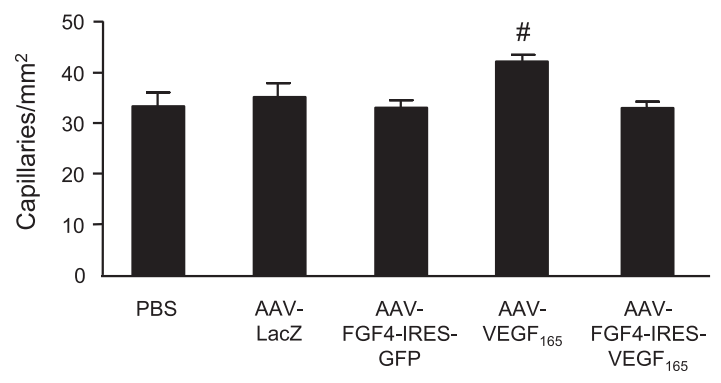

Figure 6 AAV-VEGF-A stimulates skin neovascularization in $\mathrm{db} / \mathrm{db}$ mice 21 days after wounding and gene transfer. (A) Representative pictures demonstrating isolectin B4 binding and expression of proliferating cell nuclear antigen (PCNA) (arrows). DAPI was used to confirm the nuclear localization of PCNA (arrow). (B) The number of proliferating capillary endothelial cells was increased after AAV-VEGF-A injection. (C) Total number of capillaries was also increased only after AAV-VEGF-A administration. Graphs represent means \pm SEM ( $n=5$ animals/group); ${ }^{*} p<0.05$ vs PBS and AAVLacZ; \# $p<0.05$ vs PBS. Scale bar $=0.01 \mathrm{~mm}$.

rhVEGF-A treatment, this effect most probably depends only on FGF4. Nevertheless, this rhFGF4-mediated stimulation of MMP-9 expression seems to be insufficient to significantly increase the migration of diabetic fibroblasts cultured in $25 \mathrm{mM}$ glucose DMEM, as its rate did not change upon sole rhFGF4 treatment (see Figure 7b). Thus, we have performed analysis of the expression of one of the VEGF receptors, Flt-1, as a possible mechanism responsible for this observation. Similarly to MMP9, there were no significant differences in the basal Flt-1 expression between $\mathrm{WT}$ and $\mathrm{db} / \mathrm{db}$ fibroblasts kept either in low or high glucose (Figure 8c). Sole rhVEGF treatment did not influence Flt-1 expression in diabetic 


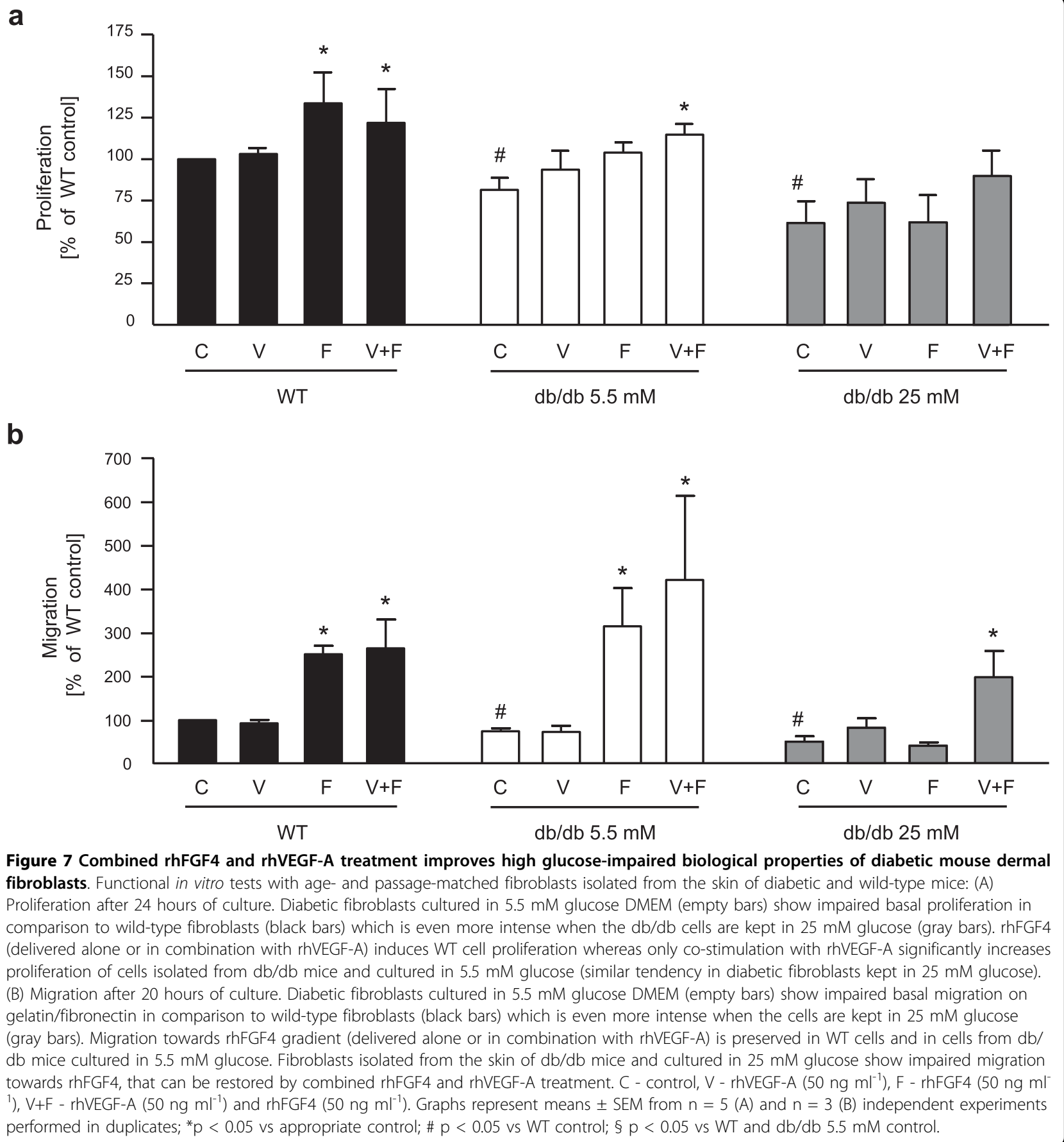

fibroblasts, but again, as in case of MMP-9, it was up-regulated by rhFGF4 with no further change by combined treatment with rhVEGF-A and rhFGF4 (Figure 8d).

\section{Discussion}

The salient finding of the present study is demonstration that combined overexpression of VEGF-A and FGF4 results in the faster wound healing in diabetic mice than single treatment. This can be a result of enhanced migration of fibroblasts stimulated by two growth factors, the process at least partially dependent on up-regulation of MMP-9 and VEGF receptor 1 expression enhanced by FGF4.

VEGF-A has been shown to play a pivotal role in the initiation of angiogenesis, based on its ability to induce the expression of proteases that digest components of the extracellular matrix that impede angiogenesis, to 
a

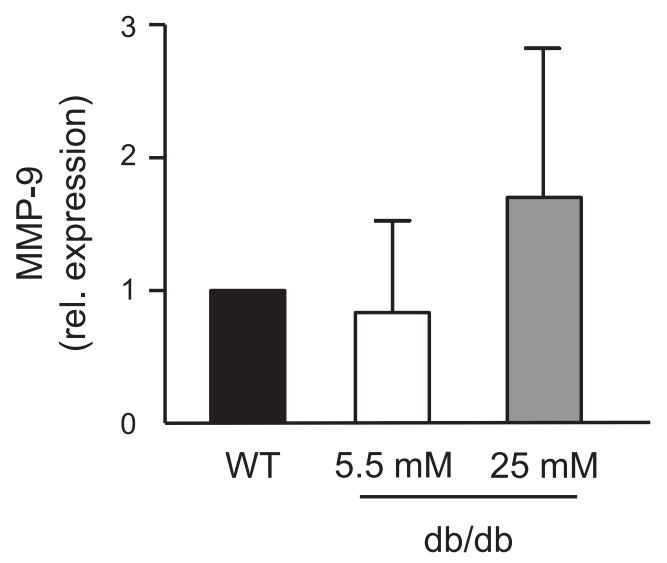

C

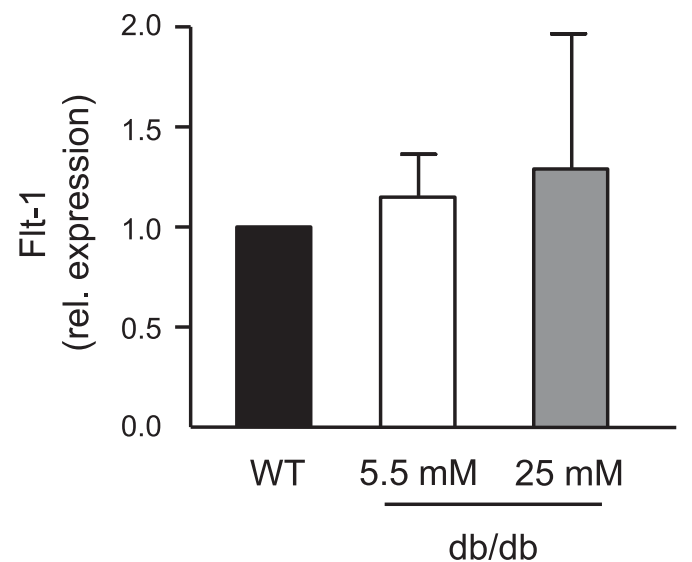

b

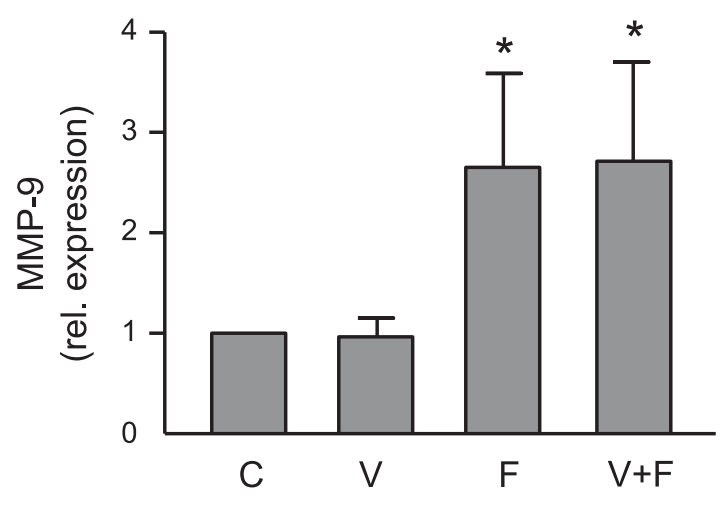

d

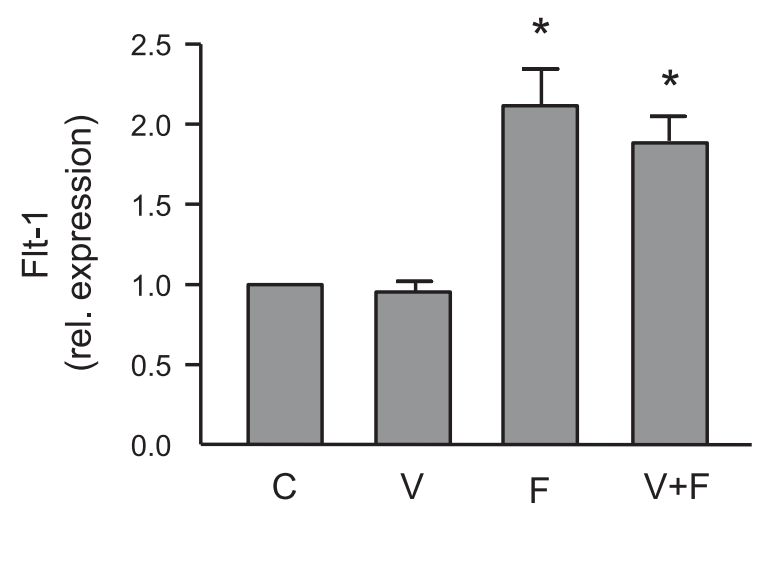

Figure 8 rhFGF4 stimulates MMP-9 and Flt-1 expression in diabetic mouse dermal fibroblasts. (A) There are no significant differences in the basal MMP-9 expression between WT and db/db fibroblasts cultured either in low (5.5 mM) or high (25 mM) glucose. (B) MMP-9 expression is up-regulated upon single rhFGF4 or combined with rhVEGF-A treatment in $\mathrm{db} / \mathrm{db}$ fibroblasts cultured in hyperglycemic conditions. (C) There are no significant differences in the basal Flt-1 expression between WT and db/db fibroblasts cultured either in low (5.5 mM) or high (25 mM) glucose. (D) Flt-1 expression is up-regulated upon single rhFGF4 or combined with rhVEGF-A treatment in db/db fibroblasts cultured in hyperglycemic conditions. C - control, $V$ - rhVEGF-A $\left(50 \mathrm{ng} \mathrm{ml}^{-1}\right), \mathrm{F}$ - rhFGF4 $\left(50 \mathrm{ng} \mathrm{ml}^{-1}\right), \mathrm{V}+\mathrm{F}-\mathrm{rhVEGF-A}\left(50 \mathrm{ng} \mathrm{ml}^{-1}\right)$ and rhFGF4 $\left(50 \mathrm{ng} \mathrm{ml}^{-1}\right)$. Graphs represent means \pm SEM from $n=3$ independent experiments performed in duplicates; ${ }^{*} p<0.05$ vs control.

promote endothelial cell proliferation, and to prevent their apoptosis $[6,8]$. In addition, it has been demonstrated that VEGF-A gene transfer improves diabetesimpaired wound healing by stimulation of angiogenesis and granulation tissue formation $[9,10]$.

In our study, the healing process after injection of AAV-VEGF-A was also accelerated when compared to PBS- or AAV-LacZ-treated animals. FGF4 delivered alone in a form of AAV-FGF4-IRES-GFP vector did not influence the rate of wound healing. So far, there were no studies investigating the role of this agent in this phenomenon. In contrary to VEGF-A, FGF4 is an oncogene and is not produced in adults under normal, physiological conditions [17]. It is very well known that disruption of the normal process of tissue regeneration in diabetes mellitus is related to the decreased production of different growth factors and VEGF-A is one of them [34-36]. Therefore, FGF4 delivered alone, although possessing the ability to up-regulate the endogenous VEGF-A expression $[19,20]$, may be ineffective in reparative processes in diabetes. In this sense, the combined therapy using FGF4 and VEGF-A coding sequences seemed to be a better approach. In fact, AAV-mediated combined gene transfer of FGF4 and VEGF-A improved diabetic wound healing over the effect exerted by AAV-VEGF-A.

Using available ELISA kits we were not able to detect any up-regulation of hVEGF-A and only slight hFGF4 
production in the skin of AAV-FGF4-IRES-VEGF-Ainjected mice at the end of the healing process. We suspect that the turnover of transduced cells might result in loss of introduced gene expression over time and finally lead to very low or lack of expression especially that at day 21 all wounds in the AAV-FGF4-IRESVEGF-A group were healed since couple of days already. Also, as demonstrated by $\beta$-galactosidase in situ staining and with the colorimetric assay in skin tissue lysates, the expression of the reporter gene 21 days after vector injection was local and rather low. Similar observation has been made by Badillo and co-workers, who used lentiviral vectors, capable of high and stable gene delivery, for the transduction of wounded skin tissue. The authors observed that 14 days post wounding and viral treatment GFP expression was limited to isolated areas or completely absent [37]. Importantly, we did not detect any hVEGF-A and any hFGF-4 in the plasma of the transduced mice (data not shown) what indicates that there was no systemic exposure to these agents and no significant side effects.

In the present study combinatory therapy with VEGF$\mathrm{A}$ and FGF4 coding sequences increased the vascularity of granulation tissue. Concerning vascularity, only mature vessels that contained erythrocytes were counted. In contrast to AAV-VEGF-A combined VEGF$A$ and FGF4 treatment did not significantly change the number of isolectin-labeled capillaries and their proliferation 21 days after gene transfer suggesting the lack of stimulatory effect on the neovascularization. On the other hand, it is very well known that upon completion of epithelialization (what in case of AAV-FGF4-IRESVEGF-A-injected animals occurred a couple of days before histological examination) cell proliferation and neovascularization cease, scar tissue forms, and the wound enters the remodeling phase [38]. One of the typical features of transformation of the granulation tissue into scar is regression of vascular structures. Therefore, the lack of effect of AAV-FGF4-IRES-VEGF-A vector on the total number of skin capillaries and their proliferation 21 days after wounding and gene transfer may be explained by the phenomenon of their natural regression.

Very recently, Brem et al. demonstrated that VEGF-A was capable of stimulating the migration of activated keratinocytes over the wound area what indicates that this growth factor can promote epithelialization independently of its role in recruiting and stimulating endothelial cells in the repair process [39]. Although, in the present study stimulation of keratinocyte migration was not investigated, we cannot exclude that it also contributed to the faster wound closure in AAV-VEGFA- and AAV-FGF4-IRES-VEGF-A-treated mice independently of the stimulation of angiogenesis.
In our hands, VEGF-A delivered alone or in combination with FGF4 into the wound edge produced a significant acceleration of the wound closure that was associated with increased thickness of granulation tissue, increased number of cells within the dermal layer and abundant collagen deposition. Collagen is the major connective-tissue component of granulation tissue, scar and dermis. Its synthesis and deposition are critical for wound closure [39].

Studies demonstrating that diabetes does have effects on essential aspects of fibroblast biology, such as proliferation and collagen synthesis, pointed at the important and complex functions of these cells during tissue repair $[33,40,41]$. Therefore, in the present study we addressed the question whether glucose concentration might somehow modulate proliferation, migration and angiogenic gene expression in diabetic dermal fibroblasts exposed to sole or combined rhVEGF-A and rhFGF4 treatment. Age- and passage-matched fibroblasts isolated from the skin of non-diabetic (WT) mice of the same background strain served as control. Diabetic fibroblasts were cultured either in low $(5.5 \mathrm{mM})$ or high $(25 \mathrm{mM})$ glucose DMEM concentration and the later was intended to resemble the diabetic environment. We have observed significant differences in basal proliferation and migration on fibronectin/gelatin between diabetic and healthy (WT) mouse dermal fibroblasts. Moreover, $\mathrm{db} / \mathrm{db}$ fibroblasts cultured in high glucose concentration $(25 \mathrm{mM})$ exhibited even more dramatic reduction in proliferation and migration rate than $\mathrm{db} / \mathrm{db}$ fibroblasts cultured in low glucose $(5.5 \mathrm{mM})$. Additionally, culture in the presence of high glucose concentration led to significantly impaired response to rhFGF4 treatment. Apparently, co-stimulation with rhFGF4 and rhVEGF-A significantly improved migration of these cells.

We have examined MMP-9 (gelatinase) expression as a possible mechanism responsible for this observation. We did not observe any significant differences in the basal MMP-9 expression between WT and db/db fibroblasts cultured either in low or in high glucose concentration. This is somehow in agreement with other data demonstrating decreased migration of $\mathrm{db} / \mathrm{db}$ fibroblasts in comparison to WT cells associated with only a selective increase in pro-MMP-9 in $\mathrm{db} / \mathrm{db}$ fibroblasts but with no difference in active MMP-9 [40].

Interestingly, we found MMP-9 gene to be significantly up-regulated in $\mathrm{db} / \mathrm{db}$ fibroblasts cultured in high glucose upon rhFGF4 treatment. Similar activity of FGF4 has been demonstrated by Anteby et al. in trophoblast suggesting its important role in early placental development [42]. Therefore, we can speculate that by increasing the invasiveness of skin fibroblasts FGF4 might also play a crucial role in the process of wound 
healing. Sole rhVEGF-A treatment did not influence MMP-9 expression in $\mathrm{db} / \mathrm{db}$ fibroblasts cultured under hyperglycemic conditions. Moreover, there was no additional up-regulation after combined rhFGF4 and rhVEGF-A treatment, what indicates that this effect depends on FGF4. Nevertheless, FGF4-mediated stimulation of MMP-9 expression seems to be insufficient to significantly increase migration of diabetic fibroblasts kept in high glucose, as its rate did not change upon sole rhFGF4 treatment. As an additional confirmation we have performed the western blot analysis of the levels of pro-MMP-9 in the tissue homogenates. We observed about 3 -fold up-regulation of this protein in the skin of animals treated with FGF-4 transgene in comparison to control animals injected with AAV-LacZ. However, due to big variability between the samples the difference was not statistically significant (data not shown).

Wang and Keiser demonstrated that VEGF-A up-regulates MMP-1, -3, and -9 expression in human smooth muscle cells (SMCs) and accelerates their migration through synthetic ECM barriers [43]. Furthermore, the authors showed expression of the high-affinity Flt-1 receptor in human SMCs and its phosphorylation upon VEGF-A treatment, suggesting its role in mediating VEGF-A action. Very recently Brem et al. demonstrated that VEGF-A stimulates migration of human fibroblasts cultured in vitro, what indicates a non-angiogenic effect of VEGF-A on wound closure [39]. In our model, we did not observe any significant in vitro effect of rhVEGF-A on primary diabetic or non-diabetic mouse dermal fibroblasts migration. Moreover, rhVEGF-A did not change Flt-1 mRNA level in those cells. Interestingly, however, we have found up-regulation of this gene expression in response to rhFGF4 in diabetic fibroblasts cultured in the presence of high glucose concentration. Moreover, there was no difference in Flt-1 expression upon single rhFGF4 or combined with rhVEGF-A treatment, what suggests the FGF4-specific effect.

\section{Conclusion}

On the basis of these findings, we can conclude that VEGF-A may increase migration of diabetic fibroblasts cultured in high glucose concentration through FGF4mediated up-regulation of one of the VEGF receptors, Flt-1. In this sense, combined therapy approach with VEGF-A and FGF4 genes may significantly improve the delayed wound repair in diabetes over the effect exerted by single VEGF-A treatment. Whether this finding might have important clinical implications remains to be established and deserves further pre-clinical and clinical investigation.

\section{Abbreviations}

AAV: adeno-associated viral vector; $\mathrm{db} / \mathrm{db}$, diabetic; Flt-1: fms-like tyrosine kinase-1 receptor (VEGF receptor 1); FGF4: fibroblast growth factor 4; MMP-9: matrix metalloproteinase-9; VEGF-A: vascular endothelial growth factor-A.

\section{Acknowledgements}

Grzegorz Dyduch, PhD, MD (Department of Clinical and Experimental Pathomorphology, Jagiellonian University, Poland) is kindly acknowledged for advise and help with histological examination. The study was supported by research grants from Ministry of Science and Higher Education, No. N302 020 31/1998 and No. PBZ-KBN-096/P05/2005 (both awarded to Jozef Dulak). Agnieszka Jazwa is the recipient of the Foundation for Polish Science (FNP) Fellowship. Alicja Jozkowicz is the recipient of the Wellcome Trust International Senior Research Fellowship. The Faculty of Biochemistry, Biophysics and Biotechnology of the Jagiellonian University is a beneficiary of the structural funds from the European Union (grant No: POIG.02.01.0012-064/08 - "Molecular biotechnology for health" and No. POIG 01.02-00-109/ 99 'Innovative methods of stem cell applications in medicine; No: POIG.02.02.00-014/08 - "Jagiellonian Centre of Experimental Therapeutics") European Union structural funds, Innovative Economy Operational Programme.

\section{Author details}

'Department of Medical Biotechnology, Faculty of Biochemistry, Biophysics and Biotechnology, Jagiellonian University, Krakow, Poland. ${ }^{2}$ Section for Studies on Metastasis, National Cancer Center Research Institute, Tokyo, Japan. ${ }^{3}$ Research \& Development Department, Adamed Ltd., Pienkow, Poland. ${ }^{4}$ A. I. Virtanen Institute, University of Kuopio and Gene Therapy Unit, Kuopio University Hospital, Kuopio, Finland.

\section{Authors' contributions}

AJ participated in the design of the study, carried out the practical work and drafted the manuscript. PK, JL, AZ, AS, JS, MK, HT, TO, RD and EV participated in the practical work and discussions. SYH and AJ participated in design of the study and helped to draft the manuscript. JD conceived of the study, designed it and edited the manuscript. All authors read and approved the final manuscript.

\section{Competing interests}

The authors declare that they have no competing interests.

Received: 9 December 2009 Accepted: 30 August 2010

Published: 30 August 2010

\section{References}

1. Falanga $\mathrm{V}$ : Wound healing and its impairment in the diabetic foot. Lancet 2005, 366(9498):1736-1743.

2. Martin P: Wound healing-aiming for perfect skin regeneration. Science 1997, 276(5309):75-81.

3. Doxey DL, Ng MC, Dill RE, lacopino AM: Platelet-derived growth factor levels in wounds of diabetic rats. Life Sci 1995, 57(11):1111-1123.

4. Werner S, Breeden M, Hubner G, Greenhalgh DG, Longaker MT: Induction of keratinocyte growth factor expression is reduced and delayed during wound healing in the genetically diabetic mouse. J Invest Dermatol 1994, 103(4):469-473.

5. Frank S, Hubner G, Breier G, Longaker MT, Greenhalgh DG, Werner S: Regulation of vascular endothelial growth factor expression in cultured keratinocytes. Implications for normal and impaired wound healing. Biol Chem 1995, 270(21):12607-12613.

6. Ferrara N: Role of vascular endothelial growth factor in regulation of physiological angiogenesis. Am J Physiol Cell Physiol 2001, 280(6): C1358-1366.

7. Pepper MS, Ferrara N, Orci L, Montesano R: Vascular endothelial growth factor (VEGF) induces plasminogen activators and plasminogen activator inhibitor-1 in microvascular endothelial cells. Biochem Biophys Res Commun 1991, 181(2):902-906.

8. Lamoreaux WJ, Fitzgerald ME, Reiner A, Hasty KA, Charles ST: Vascular endothelial growth factor increases release of gelatinase $A$ and decreases release of tissue inhibitor of metalloproteinases by microvascular endothelial cells in vitro. Microvasc Res 1998, 55(1):29-42 
9. Galiano RD, Tepper OM, Pelo CR, Bhatt KA, Callaghan M, Bastidas N, Bunting S, Steinmetz HG, Gurtner GC: Topical vascular endothelial growth factor accelerates diabetic wound healing through increased angiogenesis and by mobilizing and recruiting bone marrow-derived cells. Am J Pathol 2004, 164(6):1935-1947.

10. Galeano M, Deodato B, Altavilla D, Cucinotta D, Arsic N, Marini H, Torre V, Giacca M, Squadrito F: Adeno-associated viral vector-mediated human vascular endothelial growth factor gene transfer stimulates angiogenesis and wound healing in the genetically diabetic mouse. Diabetologia 2003, 46(4):546-555.

11. Romano Di Peppe S, Mangoni A, Zambruno G, Spinetti G, Melillo G, Napolitano M, Capogrossi MC: Adenovirus-mediated VEGF(165) gene transfer enhances wound healing by promoting angiogenesis in CD1 diabetic mice. Gene Ther 2002, 9(19):1271-1277.

12. Galzie Z, Kinsella AR, Smith JA: Fibroblast growth factors and their receptors. Biochem Cell Biol 1997, 75(6):669-685.

13. Zhang X, Ibrahimi OA, Olsen SK, Umemori H, Mohammadi M, Ornitz DM: Receptor specificity of the fibroblast growth factor family. The complete mammalian FGF family. J Biol Chem 2006, 281(23):15694-15700.

14. Ornitz DM, Itoh N: Fibroblast growth factors. Genome Biol 2001, 2(3) REVIEWS3005.

15. Feldman B, Poueymirou W, Papaioannou VE, DeChiara TM, Goldfarb M: Requirement of FGF-4 for postimplantation mouse development. Science 1995, 267(5195):246-249.

16. Niswander L, Tickle C, Vogel A, Booth I, Martin GR: FGF-4 replaces the apical ectodermal ridge and directs outgrowth and patterning of the limb. Cell 1993, 75(3):579-587.

17. Adnane J, Gaudray P, Dionne CA, Crumley G, Jaye M, Schlessinger J, Jeanteur $P$, Birnbaum D, Theillet C: BEK and FLG, two receptors to members of the FGF family, are amplified in subsets of human breast cancers. Oncogene 1991, 6(4):659-663

18. Yamamoto $H$, Ochiya $T$, Takahama $Y$, Ishii $Y$, Osumi N, Sakamoto $H_{\text {, }}$ Terada M: Detection of spatial localization of Hst-1/Fgf-4 gene expression in brain and testis from adult mice. Oncogene 2000, 19(33):3805-3810.

19. Rissanen Tा, Markkanen JE, Arve K, Rutanen J, Kettunen MI, Vajanto I, Jauhiainen S, Cashion L, Gruchala M, Narvanen O, et al: Fibroblast growth factor 4 induces vascular permeability, angiogenesis and arteriogenesis in a rabbit hindlimb ischemia model. Faseb J 2003, 17(1):100-102.

20. Deroanne CF, Hajitou A, Calberg-Bacq CM, Nusgens BV, Lapiere CM: Angiogenesis by fibroblast growth factor 4 is mediated through an autocrine up-regulation of vascular endothelial growth factor expression. Cancer Res 1997, 57(24):5590-5597.

21. Delli-Bovi P, Curatola AM, Newman KM, Sato Y, Moscatelli D, Hewick RM, Rifkin DB, Basilico C: Processing, secretion, and biological properties of a novel growth factor of the fibroblast growth factor family with oncogenic potential. Mol Cell Biol 1988, 8(7):2933-2941.

22. Dell'Era P, Belleri M, Stabile H, Massardi ML, Ribatti D, Presta M: Paracrine and autocrine effects of fibroblast growth factor- 4 in endothelial cells. Oncogene 2001, 20(21):2655-2663.

23. Aviezer D, Safran M, Yayon A: Heparin differentially regulates the interaction of fibroblast growth factor- 4 with FGF receptors 1 and 2 . Biochem Biophys Res Commun 1999, 263(3):621-626.

24. Dulak J, Jozkowicz A, Ratajska A, Szuba A, Cooke JP, Dembinska-Kiec A: Vascular endothelial growth factor is efficiently synthesized in spite of low transfection efficiency of pSG5VEGF plasmids in vascular smooth muscle cells. Vasc Med 2000, 5(1):33-40

25. Kapturczak M, Zolotukhin S, Cross J, Pileggi A, Molano RD, Jorgensen M, Byrne B, Flotte TR, Ellis T, Inverardi L, et al: Transduction of human and mouse pancreatic islet cells using a bicistronic recombinant adenoassociated viral vector. Mol Ther 2002, 5(2):154-160.

26. Sakamoto $H$, Ochiya $T$, Sato $Y$, Tsukamoto $M$, Konishi $H$, Saito I, Sugimura $T$, Terada M: Adenovirus-mediated transfer of the HST-1 (FGF4) gene induces increased levels of platelet count in vivo. Proc Natl Acad Sci USA 1994, 91(26):12368-12372.

27. Bitto A, Minutoli L, Galeano MR, Altavilla D, Polito F, Fiumara T, Calo M, Lo Cascio $P$, Zentilin L, Giacca $M$, et al: Angiopoietin-1 gene transfer improves impaired wound healing in genetically diabetic mice without increasing VEGF expression. Clin Sci (Lond) 2008, 114(12):707-718.

28. Botusan IR, Sunkari VG, Savu O, Catrina Al, Grunler J, Lindberg S, Pereira T, Yla-Herttuala S, Poellinger L, Brismar K, et al: Stabilization of HIF-1alpha is critical to improve wound healing in diabetic mice. Proc Natl Acad SCi USA 2008, 105(49):19426-19431.

29. Koda T, Hasan S, Sasaki A, Arimura Y, Kakinuma M: Regulatory sequences required for hst-1 expression in embryonal carcinoma cells. FEBS Lett 1994, 342(1):71-75

30. Coleman DL: Diabetes-obesity syndromes in mice. Diabetes 1982 , 31(Suppl 1 Pt 2):1-6

31. Mace KA, Yu DH, Paydar KZ, Boudreau N, Young DM: Sustained expression of Hif-1alpha in the diabetic environment promotes angiogenesis and cutaneous wound repair. Wound Repair Regen 2007, 15(5):636-645.

32. Inoue $Y$, Yamazaki $Y$, Shimizu T: How accurately can we discriminate Gprotein-coupled receptors as 7-tms TM protein sequences from other sequences? Biochem Biophys Res Commun 2005, 338(3):1542-1546.

33. Hehenberger K, Heilborn JD, Brismar K, Hansson A: Inhibited proliferation of fibroblasts derived from chronic diabetic wounds and normal dermal fibroblasts treated with high glucose is associated with increased formation of I-lactate. Wound Repair Regen 1998, 6(2):135-141.

34. Brown LF, Yeo KT, Berse B, Yeo TK, Senger DR, Dvorak HF, van de Water L: Expression of vascular permeability factor (vascular endothelial growth factor) by epidermal keratinocytes during wound healing. J Exp Med 1992, 176(5):1375-1379

35. Swift ME, Kleinman HK, DiPietro LA: Impaired wound repair and delayed angiogenesis in aged mice. Lab Invest 1999, 79(12):1479-1487.

36. Altavilla D, Saitta A, Cucinotta D, Galeano M, Deodato B, Colonna M, Torre V, Russo G, Sardella A, Urna G, et al: Inhibition of lipid peroxidation restores impaired vascular endothelial growth factor expression and stimulates wound healing and angiogenesis in the genetically diabetic mouse. Diabetes 2001, 50(3):667-674.

37. Badillo AT, Chung S, Zhang L, Zoltick P, Liechty KW: Lentiviral gene transfer of SDF-1alpha to wounds improves diabetic wound healing. J Surg Res 2007, 143(1):35-42.

38. Eming SA, Brachvogel B, Odorisio T, Koch M: Regulation of angiogenesis: wound healing as a model. Prog Histochem Cytochem 2007, 42(3):115-170.

39. Brem H, Kodra A, Golinko MS, Entero H, Stojadinovic O, Wang VM, Sheahan CM, Weinberg AD, Woo SL, Ehrlich HP, et al: Mechanism of Sustained Release of Vascular Endothelial Growth Factor in Accelerating Experimental Diabetic Healing. J Invest Dermatol 2009, 129(9):2275-87.

40. Lerman OZ, Galiano RD, Armour M, Levine JP, Gurtner GC: Cellular dysfunction in the diabetic fibroblast: impairment in migration, vascular endothelial growth factor production, and response to hypoxia. Am J Pathol 2003, 162(1):303-312.

41. Goldstein S, Moerman EJ, Soeldner JS, Gleason RE, Barnett DM: Diabetes mellitus and genetic prediabetes. Decreased replicative capacity of cultured skin fibroblasts. J Clin Invest 1979, 63(3):358-370.

42. Anteby EY, Greenfield C, Natanson-Yaron S, Goldman-Wohl D, Hamani $Y$, Khudyak V, Ariel I, Yagel S: Vascular endothelial growth factor, epidermal growth factor and fibroblast growth factor- 4 and -10 stimulate trophoblast plasminogen activator system and metalloproteinase-9. $\mathrm{Mol}$ Hum Reprod 2004, 10(4):229-235.

43. Wang $H$, Keiser JA: Vascular endothelial growth factor upregulates the expression of matrix metalloproteinases in vascular smooth muscle cells: role of flt-1. Circ Res 1998, 83(8):832-840.

doi:10.1186/1479-0556-8-6

Cite this article as: Jazwa et al:: Combined vascular endothelial growth factor-A and fibroblast growth factor 4 gene transfer improves wound healing in diabetic mice. Genetic Vaccines and Therapy 2010 8:6. 